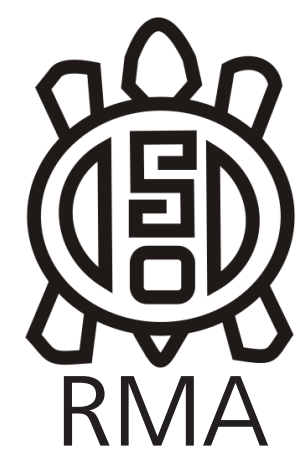

Arqueología

\title{
El Túmulo II del Brazo Largo. Aportes para la arqueología del Delta Inferior del río Paraná
}

\author{
Túmulo II del Brazo Largo. A contribution to the archaeology of the \\ Paraná Lower Delta
}

Gustavo Politis*, Laura Bastourre ${ }^{* *}$, Violeta Di Prado**, Mariano
Bonomo $o^{* *}$
Germán Moreira ${ }^{* * *}$ y Alejandra Matarrese

* INCUAPA-CONICET, Universidad Nacional del Centro de la Provincia de Buenos Aires y

División Arqueología, Facultad de Ciencias Naturales y Museo, Universidad Nacional de La Plata. E-mail: gpolitis@ fcnym.unlp.edu.ar; ** CONICET-División Arqueología, Facultad de Ciencias Naturales y Museo, Universidad Nacional de La Plata. E-mails: laurabastourre@yahoo.com.ar, violetadiprado@hotmail.com, mbonomo@fcnym.unlp.edu.ar;

*** CIC-División Arqueología, Facultad de Ciencias Naturales y Museo, Universidad Nacional de La Plata. E-mail: gmoreira@fcnym.unlp.edu.ar; ****Facultad de Ciencias Naturales y Museo, Universidad Nacional de La Plata y LEIA, Universidade Federal de Santa Catarina/CNPq. E-mail: alejandra.matarrese@gmail.com

\begin{abstract}
Resumen
En este trabajo se presentan los resultados del análisis de la colección del Túmulo Il del Brazo Largo (Delta Inferior del Paraná), datada en circa 750 años ${ }^{14} \mathrm{C}$ AP. El registro arqueofaunístico se caracteriza por el predominio de Blastocerus dichotomus, seguido de Myocastor coypus, Hydrochoerus hydrochaeris y peces. Se registró también un abundante y diverso conjunto de carnívoros, con evidencias de una intensa actividad de cuereo. Los artefactos óseos exhiben una amplia variedad de grupos morfológicos y evidencias de todo el proceso de manufactura de los cabezales de arpón. El conjunto cerámico se caracteriza por el predominio de formas abiertas, de tamaño mediano, paredes rectas y bases convexas. Las variantes del inciso y los elementos de diseño son similares a los referidos por otros autores para el Delta Inferior, pero algunas representaciones decorativas exhiben una distribución espacial más amplia. El conjunto lítico comprende artefactos picados y/o abradidos con escasa formatización, artefactos fracturados reciclados y piezas agotadas. La tecnología ósea, lítica y cerámica essemejante a la de otros sitios arqueológicos del Delta Inferior. Las diferencias de estos sitios con los asignados a Goya-Malabrigo probablemente reflejen la diversidad cultural descrita en las fuentes históricas del siglo XVI para el Delta del Paraná.
\end{abstract}

Palabras clave: montículos; Nordeste Argentino; Holoceno tardío; colecciones de museo.

\begin{abstract}
In this paper we present the results of the analysis of the Túmulo II del Brazo Largo collection (Lower Delta of the Paraná River), dated circa $750{ }^{14} \mathrm{C}$ years BP. The archaeofaunal assemblage is dominated by Blastocerus dichotomus, followed by Myocastor coypus, Hydrochoerus hydrochaeris and fish. Also, a numerous and diverse carnivore bone assemblage, which shows clear evidences of skinning, was identified. The bone tool collection presents a wide variety of morphological groups and evidences of harpoon heads manufacture sequence were recorded. The ceramic materials are characterized by the predominance of open medium-sized shapes, with straight walls and convex bases. Incising modes and design elements depicted in the pottery are similar to those reported by other authors in the Paraná Lower Delta, but some decorative units present a wider spatial distribution. The lithic assemblage comprises ground stone tools with little effort invested in their shaping, recycled broken artefacts and worn-out pieces. The bone, lithic and ceramic technology is similar to that described for other archaeological sites in the Lower Delta. The differences between these sites and Goya-Malabrigo contexts probably reflect the cultural diversity described for the Paraná Delta by early sixteenth century historical sources.
\end{abstract}

Keywords: mounds; Argentinean North-East; Late Holocene; museum collections.

En este trabajo se presentan los resultados del análisis de la colección del sitio Túmulo II del Brazo Largo (TIIBL), ubicado en el Delta Inferior del río Paraná (provincia de Entre Ríos) y cuyos materiales se encuentran almacenados en el Depósito 25 de la División Arqueología del Museo de La Plata (MLP), Universidad Nacional de La Plata (UNLP)1. El "túmulo" fue excavado en 1923 por Octavio

${ }^{1}$ Este trabajo es una versión expandida de la ponencia presentada
por los autores en el Sexto Encuentro de Discusión Arqueológica del 
Fernández (preparador del MLP) y Pablo Gaggero (Ayudante del Instituto del Museo de la UNLP), quien entre 1921 y 1925 realizó numerosos viajes en comisiones arqueológicas y antropológicas al Delta del Paraná. Una de las características de la colección es que posee muy buena información asociada. Gaggero escribió un informe inédito que se encuentra en el archivo de la División Arqueología de dicho museo y que posee información detallada sobre las tareas de campo (Gaggero 1923). Además de una descripción de la excavación (junto con un croquis) y de los hallazgos principales, este informe incluye un mapa con la ubicación del sitio y seis fotos del montículo y de los trabajos de campo. También se dispone de información complementaria en la documentación de las colecciones de la División Arqueología del MLP. Los materiales estaban en cajas separadas y no se detectaron inconsistencias en las etiquetas ni en los números de catálogo que figuran en el citado informe.

A pesar de que pasaron más de 90 años desde su recuperación y de la abundancia y riqueza de los materiales, la colección de este sitio no había sido estudiada de manera sistemática, ni tampoco había sido publicada de manera integral. Una excepción la constituye el estudio realizado por Bonomo et al. (2009) sobre una parte importante de los artefactos óseos, restos faunísticos y materiales líticos y cerámicos recuperados en este sitio. Recientemente, Mazza (2015) analizó los restos óseos humanos del sitio y los incluyó en una revisión sobre la bioarqueología de la zona. Entre las características destacadas, menciona en uno de los cráneos (MLPDA-6079) una decoloración verdosa que asigna a óxido de cobre. Una revisión pormenorizada de estos restos se halla en curso por Clara Scabuzzo y Agustina Ramos van Raap. El Túmulo II del Brazo Largo no debe confundirse con otros sitios cercanos, con nombres parecidos, que se encuentran cerca del cauce del Brazo Largo y sobre los cuales hay algunas publicaciones: el Túmulo I del Brazo Largo (Torres 1911; véase también Caggiano 1979: 110) y Brazo Largo (Gatto 1939) (Figura 1).

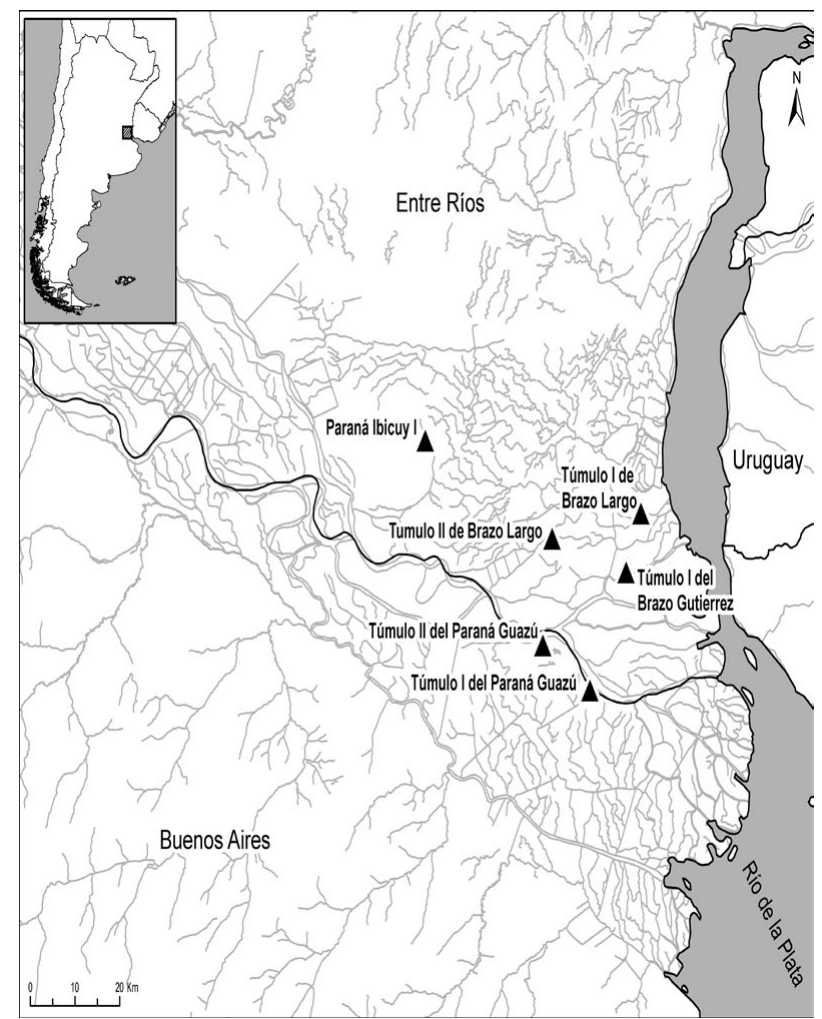

Figura 1. Ubicación del Túmulo II del Brazo Largo y otros sitios mencionados en el texto.

Figure 1. Location of the Túmulo II del Brazo Largo and other sites mentioned in the text.

El primer objetivo de este trabajo es presentar el resultado de los estudios de los materiales cerámicos, líticos y faunísticos de la colección, algunos de ellos con características excepcionales, e integrar la información obtenida con la que proviene de sitios arqueológicos cercanos. El segundo objetivo es discutir algunos modelos que se han propuesto para interpretar el registro arqueológico del Delta Inferior del río Paraná, especialmente para el sector de islas (Acosta et al. 2013; Caggiano 1984; Loponte et al. 2012; Serrano 1972; Torres 1911).

Nordeste Argentino, Gualeguaychú, 23 al 26 de septiembre de 2015.

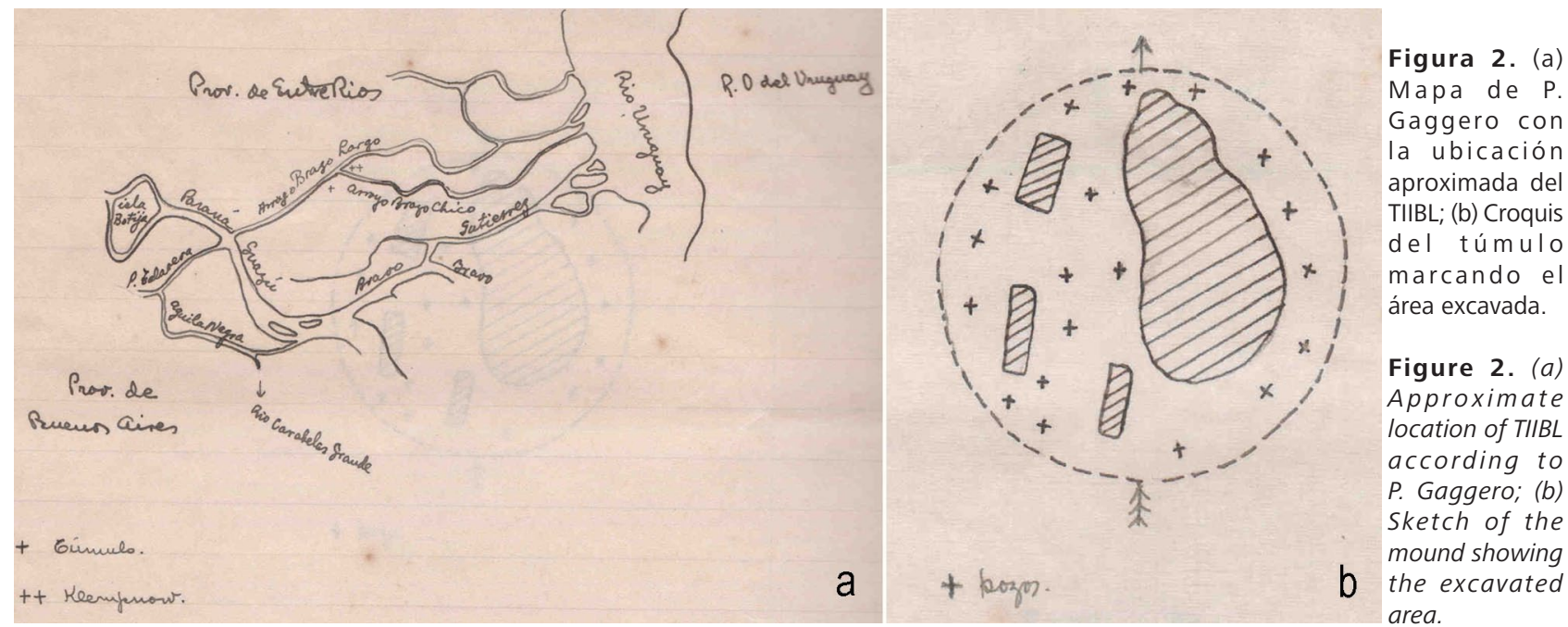




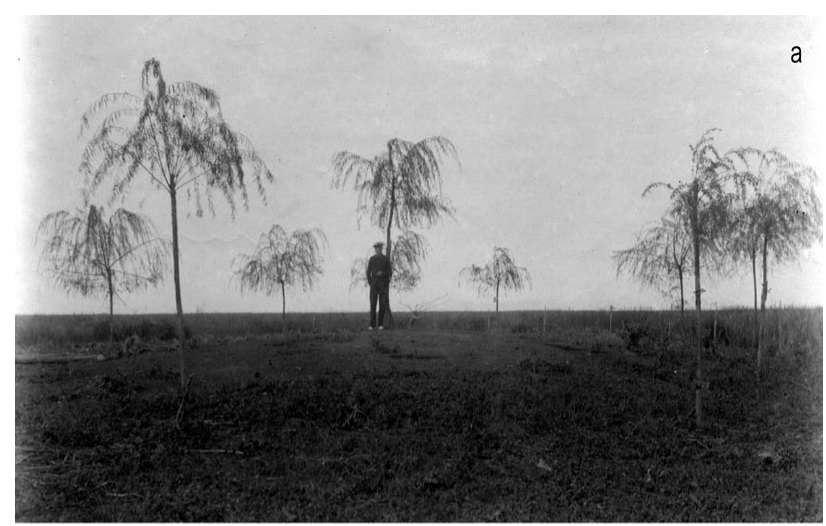

b

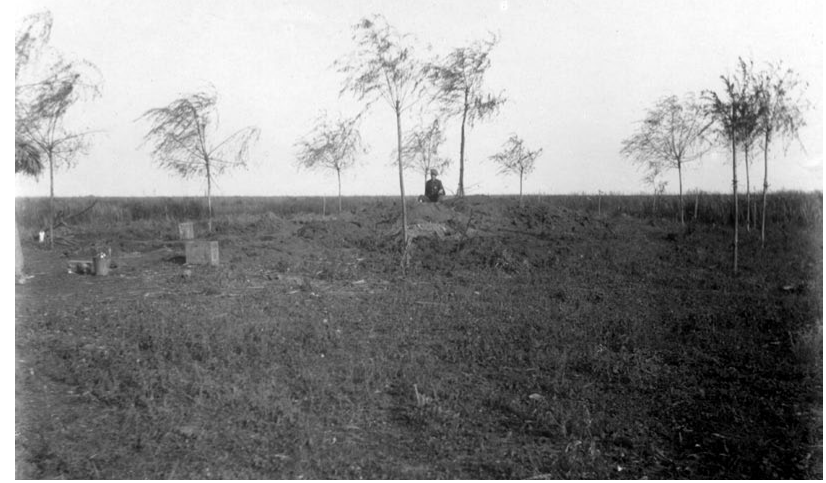

Figura 3. Fotos del túmulo antes (a) y al final de la excavación. En el centro Sr. O. Fernández.

Figure 3. Pictures of the mound before (a) and after the excavation. Mr. O. Fernández is in the centre of the image.

\section{Ubicación y trabajos de campo}

El sitio fue encontrado por Reinhold Vogel, un vecino de Buenos Aires, quien ya había enviado una pequeña cantidad de restos óseos humanos y objetos arqueológicos al MLP. Se localiza en la confluencia del arroyo Brazo Largo con el arroyo Chico, aproximadamente a los $33^{\circ} 48^{\prime} 25^{\prime \prime} \mathrm{S}$ y $58^{\circ} 46^{\prime} 32^{\prime \prime} \mathrm{O}$ (Figura 1). No está sobre ninguno de los dos cursos de agua y Gaggero y Fernández debieron caminar unos 30 minutos desde la orilla hasta donde está el túmulo (Figura 2 a).

El trabajo de campo se llevó a cabo entre el 24 de mayo y el 1 de junio de 1923 y durante la estadía los investigadores se alojaron muy cerca, en la casa de un poblador, el Sr. Klempnow (doble cruz en Figura 2 a). En el informe de 1923 Gaggero expresa que el aspecto del túmulo es "típico", de forma circular con unos $28 \mathrm{~m}$ de diámetro, y se distingue como una "loma perfecta", con tierra negra en la parte superior y arena en la base. Se encuentra en la parte más elevada de un "gran pajonal bastante alejado del albardón que corre paralelo al Brazo Largo" (Gaggero 1923: 2) (Figura 3). Los árboles que se ven en las fotos son sauces plantados por los pobladores. Gaggero observa que el lugar era usado por los animales en las inundaciones, lo que produce deterioro de los materiales arqueológicos y la erosión del túmulo. Describe que cuando "la tierra está mojada al introducirse las patas [del ganado] se fracturan muchos huesos" (Gaggero 1923: 2). Justamente, como se observa en la Figura 3, la superficie del túmulo no presentaba cobertura vegetal durante la intervención del sitio arqueológico.

Las excavaciones se iniciaron cerca del centro del montículo, ligeramente al NE (Figura 2 b, Figura 3 b). Se hicieron varias zanjas (rayado oblicuo en la Figura 2 b) y más tarde pozos a pala a poca distancia uno de otro (cruces en la Figura 2 b). En los pozos del lado $\mathrm{S}$ y $\mathrm{O}$ hallaron "huesos de ciervo y otros mamíferos, fragmentos de cerámica, varias piedras, cocos quebrados, pitos de hueso, etc." (Gaggero 1923: 3). Se reconoció además un trozo de "árbol petrificado no muy rodado". Además del

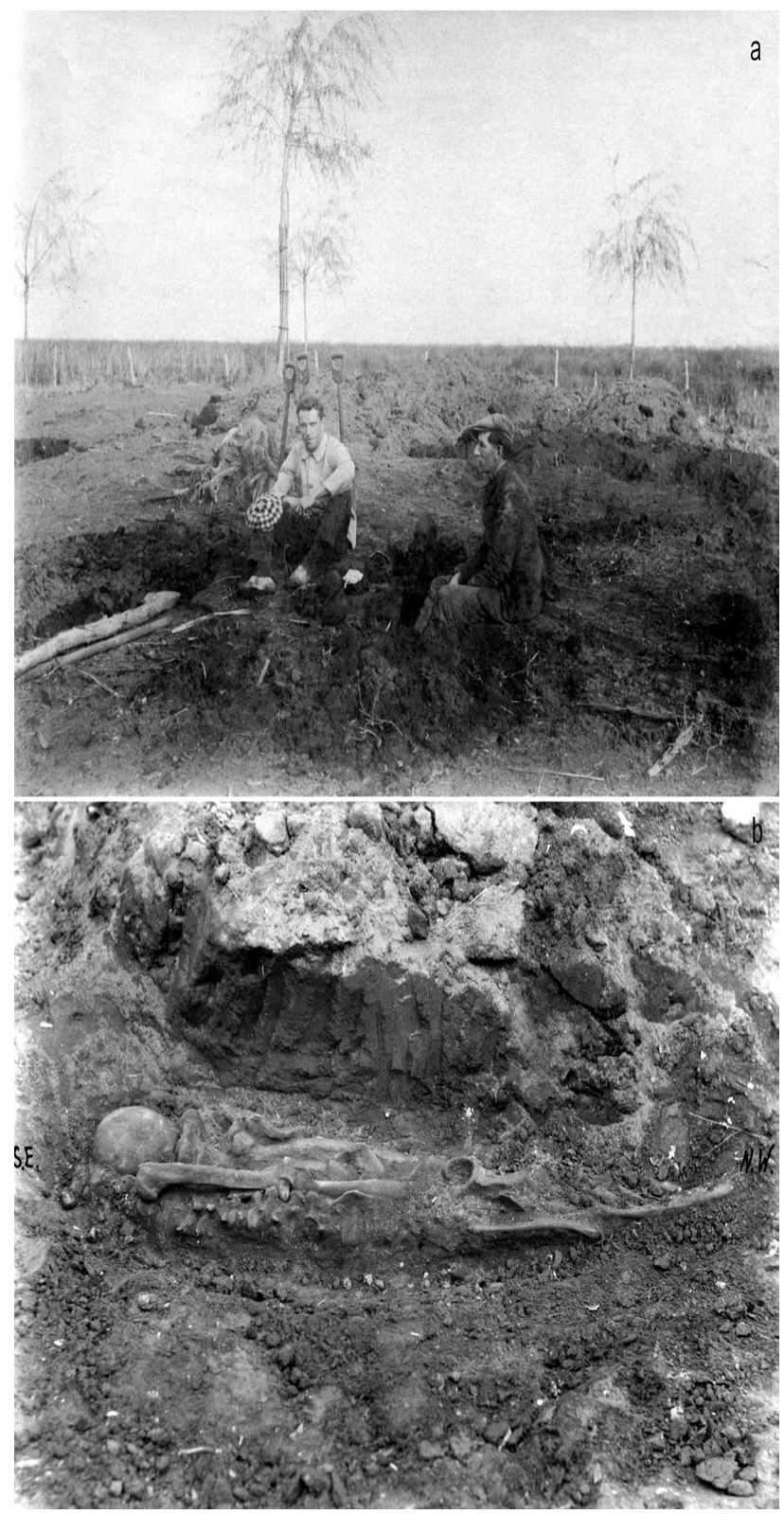

Figura 4. (a) "Detalle de la excavación desde el SO. 30 de mayo de 1923" (Gaggero 1923: 4) y (b) restos humanos del sitio.

Figure 4. (a) "Detail of the excavation (view from SW). May 30th, 1923" (Gaggero 1923: 4) and (b) human remains recovered at the site. 
material lítico y cerámico, hallaron numerosos cráneos humanos y huesos del esqueleto poscraneal distribuidos en la "falda oriental del túmulo, más extendidos en el cuadrante norte de la misma falda" (Gaggero 1923: 4) y se identificaron "varios huesos patológicos" que pertenecerían al mismo individuo. Reconocieron que entre los huesos de un esqueleto había varios restos óseos pertenecientes a otros individuos; por ejemplo, en la región pectoral de un esqueleto, entre las costillas, hallaron un fragmento de pelvis. El esqueleto $n^{\circ} 1$ tenía una dirección SE (la cabeza) a NO (las extremidades) (Figura 4 b).

Se ha obtenido una sola datación radiocarbónica realizada sobre restos humanos, específicamente sobre una costilla derecha de un individuo adulto (MLP-DA-6357), que permite ubicar temporalmente los materiales arqueológicos en $756 \pm 46$ años ${ }^{14} \mathrm{C}$ (AA-103898), lo que calibrado en años calendáricos (Calib 6.19) arroja edades de 1222-1323 AD (2 sigmas) y 1266-1314 AD (1 sigma). Esta edad se encuentra dentro del rango temporal de los sitios del Delta del Paraná Inferior con características similares (Bonomo et al. 2011a: tabla 4). Sin embargo, hay que remarcar que esta datación marca solo un corto lapso de tiempo dentro de una secuencia de ocupación que probablemente fue más larga.

\section{Materiales y metodología}

Los materiales conservados en la División Arqueología del MLP comprenden restos de fauna $(n=460)$, artefactos de hueso $(n=59)$, tiestos $(n=392)$ y materiales líticos $(n=28)$. Además, en la División Antropología del MLP se encuentra depositada una colección de restos óseos humanos provenientes del sitio, cuyo estudio no será abordado en esta contribución.

El análisis de la alfarería se realizó mediante el relevamiento a nivel macroscópico de las técnicas constructivas (Balfet et al. 1992; Rye 1981: 67-68), los tratamientos de superficie (Di Prado 2015: 73-76; López 2000-2002: 352-353) y las representaciones decorativas plasmadas mediante variantes del inciso (Convención Nacional de Antropología 1966). Los elementos de diseño fueron delimitados de acuerdo con Bugliani (2008) y Di Prado (2015). La descripción de la forma y el tamaño de las piezas se realizó de acuerdo con Balfet et al. (1992: 19) y Bugliani (2008: 26). Estas categorías formales se aplicaron en aquellos bordes incluidos en el número mínimo de vasijas (NMV), estimado con base en la propuesta de Feely y Ratto (2013). Las alteraciones por uso (e.g. depósitos de hollín y esquirlas) se registraron de acuerdo con Skibo (1992: 44, 106) y Vieugué (2014: 627).

La identificación de los especímenes óseos fue realizada utilizando colecciones de referencia depositadas en el MLP, atlas osteológicos y bibliografía especializada (e.g. Segura et al. 2013; Tedford et al. 1995). Se calcularon

\begin{tabular}{lll}
\hline Taxón & NISP & MNI \\
\hline Actinopterygii & 3 & - \\
Siluriformes & 7 & - \\
Pseudoplatystoma sp. & 1 & 1 \\
Doradidae & 18 & - \\
Pterodoras granulosus & 3 & 1 \\
Phrynops hilarii & 1 & - \\
Falconiformes & 1 & - \\
Mammalia (grande) & 111 & - \\
Cerdocyon thous & 10 & 3 \\
Chrysocyon brachyurus & 4 & 2 \\
Felidae & 1 & - \\
Oncifelis geoffroyi & 8 & 3 \\
Lynchailurus pajeros & 2 & 1 \\
Herpailurus yagouaroundi & 2 & 1 \\
Galictis cuja & 4 & 2 \\
Lontra longicaudis & 3 & 1 \\
Artiodactyla & 13 & - \\
Blastocerus dichotomus & 165 & 21 \\
Ozotoceros bezoarticus & 2 & 1 \\
Hydrochoerus hydrochaeris & 14 & 2 \\
Myocastor coypus & 86 & 28 \\
\hline Total & 459 & - \\
\hline
\end{tabular}

Tabla 1. Valores de NISP y NMI para los taxones identificados en TIIBL.

Table 1. NISP and MNI values for each taxon identified at TIIBL.

\begin{tabular}{lcccc}
\hline \multicolumn{5}{c}{ Blastocerus dichotomus } \\
Elemento & NISP & MNE & MAU & MAU\% \\
\hline Asta & 7 & - & - & - \\
Cráneo & 9 & 5 & 5 & $29,41 \%$ \\
Hemimandibula & 22 & 12 & 6 & $35,29 \%$ \\
Dientes sueltos & 11 & - & - & - \\
Vértebras & 1 & 1 & 0,03 & $0,18 \%$ \\
Húmero & 3 & 3 & 1,5 & $8,82 \%$ \\
Radio & 6 & 5 & 2,5 & $14,71 \%$ \\
Ulna & 9 & 9 & 4,5 & $26,47 \%$ \\
Metacarpo & 3 & 3 & 1,5 & $8,82 \%$ \\
Tibia & 14 & 7 & 3,5 & $20,59 \%$ \\
Rótula & 2 & 2 & 1 & $5,88 \%$ \\
Metatarso & 13 & 7 & 3,5 & $20,59 \%$ \\
Astrágalo & 34 & 34 & 17 & $100,00 \%$ \\
Calcáneo & 19 & 19 & 9,5 & $55,88 \%$ \\
Falange 1 & 2 & 2 & 0,2 & $1,18 \%$ \\
Falange 2 & 7 & 7 & 0,9 & $5,29 \%$ \\
Falange 3 & 3 & 3 & 0,4 & $2,35 \%$ \\
\hline
\end{tabular}

Tabla 2. Medidas de abundancia anatómica para Blastocerus dichotomus.

Table 2. Abundance measures for Blastocerus dichotomus.

diferentes medidas de abundancia: NISP, NMI, MNE, MAU y MAU\% (Lyman 2008; Mengoni Goñalons 2010) y se realizó un examen macroscópico y con lupa binocular de las superficies óseas con el objetivo de identificar alteraciones de origen natural y antrópico. Se relevó el grado de meteorización de los restos óseos (Andrews 1990; Behrensmeyer 1978), así como los estadios de 
Tabla 3. Restos óseos asignados a carnívoros en TIIBL.

Table 3. Carnivore bone assemblage of TIIBL.

\begin{tabular}{lcccccc}
\hline & Taxón & \multicolumn{5}{c}{ Elemento } \\
& & Cráneo MaxilarPremaxilarHemimandibulaPoscráneo \\
\multirow{2}{*}{ Canidae } & Cerdocyon thous & 1 & 2 & 1 & 6 & 0 \\
& Chrysocyon brachyurus & 0 & 3 & 1 & 0 & 0 \\
\multirow{3}{*}{ Felidae } & Oncifelis geoffroyi & 1 & 3 & 0 & 4 & 0 \\
& Lynchailurus pajeros & 0 & 0 & 0 & 2 & 0 \\
& Herpailurus yagouaroundi & 1 & 0 & 0 & 1 & 0 \\
\multirow{2}{*}{ Mustelidae } & Indeteminado & 0 & 0 & 0 & 1 & 0 \\
& Galictis cuja & 2 & 0 & 0 & 2 & 0 \\
\hline
\end{tabular}

abrasión y pulimento ligados a la acción hídrica (Gutiérrez y Kaufmann 2007). Además, se registró la presencia de marcas de carnívoros, roedores, pisoteo, improntas de raíces y depositación química (Fisher 1995; Gutiérrez 2004; Lyman 1994). Se identificaron las marcas de procesamiento (huellas de corte, raspado, percusión y aserrado) y se analizó su ubicación, frecuencia, morfología (profundidad, orientación y largo) y asociación con diferentes rasgos de la topografía ósea (Mengoni Goñalons 2010). A partir de la comparación con marcos de referencia propuestos por diferentes autores (Binford 1981; Escosteguy y Vigna 2010; Lloveras et al. 2009; Mallye 2011), este análisis permitió inferir las diferentes operaciones (cuereo, desarticulación, descarne, etc.) vinculadas al procesamiento y consumo de las carcasas. Por último, se registraron las termoalteraciones y los patrones de fractura. Con el objetivo de evaluar los procesos que dieron origen a la fragmentación, se calculó el índice de fractura fresca (IFF) de acuerdo con la metodología propuesta por Outram (2001).

El análisis de los restos óseos con evidencias tecnológicas estuvo dirigido a conocer la variabilidad morfológica del conjunto artefactual y a identificar los procedimientos técnicos utilizados durante su proceso de manufactura. Los elementos tecnológicos fueron identificados taxonómica y anatómicamente y clasificados en desechos de manufactura, preformas e instrumentos terminados. Asimismo, se identificaron los procedimientos (seccionamiento, retoque, aguzamiento, ahuecado, perforación, entre otros) y técnicas de manufactura (fractura, raspado, abrasión, pulido, ranurado, aserrado e incisión) de acuerdo con los criterios especificados en Averbouh (2000). Los instrumentos óseos terminados fueron clasificados en grupos morfológicos tomando como base la propuesta de Pérez Jimeno y Buc (2010), con algunas modificaciones (Bonomo et al. 2009).

Los materiales líticos fueron abordados desde un enfoque tecno-morfológico y morfológico-funcional utilizando los lineamientos metodológicos propuestos por Babot (2004) y Adams (2002). Para tal fin, se consideraron caracteres que permitieran describir, principalmente, la selección de las materias primas y de las formas-base naturales, así como las modificaciones morfológicas a las que estas últimas fueron sujetas por la manufactura (Babot 2004). De manera paralela, en el análisis morfológico-funcional se describieron caracteres morfológicos para distinguir las zonas activas, de prensión o apoyo, a partir de los cuales se consideraron los tipos y modos de acción (Babot 2004). Los diferentes caracteres macroscópicos registrados comprendieron: materia prima, forma-base, estado de conservación de la pieza, alteraciones naturales, dimensiones absolutas y relativas, formas de la pieza, caras y oquedades, modalidad de manufactura, serie técnica, rastros de uso macroscópicos, modos de acción, tipo de artefacto según el número y función de las zonas activas y designación morfológico-funcional del artefacto.

\section{Resultados}

\section{Registro arqueofaunístico}

La muestra arqueofaunística analizada comprende 459 especímenes óseos (Tabla 1). Además, se registró la presencia de un resto fósil silicificado correspondiente a un fragmento de tejido trabecular de un vertebrado de gran tamaño que no pudo identificarse y que podría proceder de sedimentos marinos de la Formación Paraná. La colección cuenta también con restos de moluscos asignados a Pomacea canaliculata $(n=2)$, Olivan cillaria sp. (un resto fósil) y abundantes restos de bivalvos (principalmente Diplodon sp.) y gasterópodos (ampuláridos) (véase Bonomo et al. 2009). Por último, la colección se completa con 59 artefactos óseos.

El mamífero mejor representado entre los restos óseos de la colección, en términos de NISP, es Blastocerus dichotomus (ciervo de los pantanos), con un NMI de 21 (en base a astrágalos), incluyendo 3 individuos juveniles. El perfil esqueletario de Blastocerus dichotomus se caracteriza por la sobrerrepresentación de ciertos elementos (e.g. astrágalos y calcáneos), mientras que otras partes esqueletarias se registran en proporciones muy bajas (e.g. vértebras y huesos largos) o están ausentes (e.g. cinturas y costillas) (Tabla 2). Además, se registraron numerosos fragmentos de huesos largos asignados a mamífero grande o Artiodactyla $(n=114)$ que carecen de atributos diagnósticos para una identificación más precisa pero que, debido a su tamaño, probablemente correspondan a este ciervo. Entre los cérvidos, se identificaron además dos fragmentos de asta asignados a Ozotoceros bezoarticus (venado de las pampas).

Con respecto a los roedores, Myocastor coypus (coipo) 
se encuentra representado por escasos restos de cráneo $(\mathrm{MNE}=1)$ y esqueleto apendicular $(\mathrm{MNE}=16)$ y numerosas hemimandíbulas $(\mathrm{MNE}=50)$. Este último elemento, que constituye el 58\% del NISP, permitió calcular un NMI de 28. Se registraron varios elementos del esqueleto axial (MNE=6) y apendicular $(\mathrm{MNE}=7)$ de Hydrochoerus hydrochaeris (carpincho), especie para la que se identificaron al menos dos individuos, uno juvenil y otro adulto.

Una característica excepcional de la colección es la gran cantidad y diversidad de carnívoros que presenta, los cuales están representados mayormente por cráneos y hemimandíbulas en muy buen estado de preservación y completitud (MLP-Ar-22.711, 22.712 y 22.750 a 22.773) (Tabla 3). Se registraron dos especies de cánidos, Cerdocyon thous (zorro de monte) y Chrysocyon brachyurus (aguará guazú), tres especies de félidos, Oncifelis geoffroyi (gato montés), Lynchailurus pajeros (gato de los pajonales) y Herpailurus yagouaroundi (yaguarundí), y dos de mustélidos, Galictis cuja (hurón menor) y Lontra longicaudis (lobito de río) (Tabla 1). A partir de la documentación disponible en el archivo de la División Arqueología del MLP, sabemos que gran parte de estos elementos (MLP-Ar-22.764 a 22.771) se encontraron asociados a un cráneo humano (MLP-Ar-6131 ex $N^{\circ}$ 7031). Específicamente, se recuperaron asociados a este cráneo los siguientes restos de carnívoros: tres restos (entre cráneos y fragmentos craneales) de Oncifelis geoffroyi, un premaxilar de Chrysocyon brachyurus y los cráneos de Herpailurus yagouarundi y Lontra longicaudis.

El conjunto ictioarquelógico es escaso y comprende fundamentalmente espinas de armados, restos de cráneo y cintura de Pterodoras granulosus (armado común) y un basioccipital asignado a Pseudoplatystoma sp. (surubí). Por último, las aves se hayan representadas solo por un húmero de Falconiformes y los reptiles por una hemipelvis asignada a Phrynops hilarii (tortuga de laguna).

La mayoría de los restos óseos se encuentran levemente meteorizados (estadio 1; 47,8\%). Los estadios moderados 2 y 3 se registraron en menores porcentajes (17\% y $6,2 \%$ respectivamente), mientras que un $28,7 \%$ de los restos no presentó meteorización. Por otra parte, se detectaron especímenes óseos (20\%) con superficies brillosas y textura suave y/o con bordes redondeados, alteraciones que pueden relacionarse con el transporte fluvial o la abrasión sedimentaria in situ (estadio 1: 7\%; estadio 2: 10,7\%; estadio 3: 0,5\%; estadio 2-3: 1,8\%). Se registraron elevados porcentajes de improntas de raíces $(41,8 \%)$, mientras que algunos especímenes presentan marcas de pisoteo $(5,2 \%)$, roedores $(1,7 \%)$ y carnívoros (1\%). Por último, la depositación química es muy frecuente, tanto de óxido de manganeso $(75,3 \%)$ como de carbonato $(49,8 \%)$.

Las modificaciones de origen antrópico se detectaron sobre la mayoría de los taxones identificados en la colección. En el caso de Blastocerus dichotomus, se registraron huellas de corte y raspado sobre 71 especímenes óseos. Son muy frecuentes las huellas a nivel del tarso, principalmente ubicadas sobre la cara dorsal y medial de los astrágalos $(n=19)$ y sobre el cuerpo y la cara lateral del calcáneo $(n=11)$. Estas huellas, junto con las ubicadas en la epífisis distal de la tibia $(n=1)$, epífisis proximal del metatarso $(n=1)$ y rótula $(n=1)$ podrían atribuirse a operaciones de desarticulación del miembro posterior. Asimismo, la desarticulación a nivel del codo se infiere a partir de las huellas registradas en la epífisis distal del húmero $(n=3)$ y en la región proximal de la ulna $(n=6)$ y el radio $(n=2)$. Por otra parte, las huellas ubicadas sobre la diáfisis de huesos largos como tibia $(n=9)$, radio $(n=2)$ y ulna $(n=1)$ pueden vincularse al descarne. Además, varios fragmentos de diáfisis de huesos largos asignados a las categorías Artiodactyla y mamífero grande indeterminado $(n=24)$ presentaron huellas de corte. En el esqueleto apendicular del ciervo de los pantanos, se detectaron también marcas antrópicas sobre las diáfisis de metapodios $(n=4)$ y falanges $(n=2)$, que pueden asociarse con actividades de cuereo y/o remoción de tendones. En el esqueleto axial son numerosas las huellas en distintos sectores de la hemimandíbula. Mientras que las marcas dispuestas sobre el borde antero-inferior de este elemento, cerca de la sínfisis $(n=3)$, pueden atribuirse a operaciones de cuereo, las ubicadas a lo largo del cuerpo $(n=3)$, rama ascendente $(n=1)$, apófisis coronoides $(n=1)$ y cóndilo $(n=1)$ probablemente se asocien con la desarticulación y obtención de los músculos de la mandíbula.

Los restos óseos asignados a roedores también presentan huellas de corte atribuibles a actividades de cuereo,

Tabla 4. Restos óseos con evidencias tecnológicas según taxón y unidad anatómica.

Table 4. Bone specimens with technological evidences grouped by taxa and anatomical unit.

\begin{tabular}{|c|c|c|c|}
\hline Taxón & Unidad anatómica & Tipo de artefacto & $\mathrm{N}$ \\
\hline & & Bisel & 1 \\
\hline & Ulna & Punta plana con epífisis & 2 \\
\hline Blastocerus & & Punta cónica & 3 \\
\hline \multirow[t]{6}{*}{ dichotomus } & & Horqueta con perforación & 1 \\
\hline & Asta & Preforma & 10 \\
\hline & & Desechos de manufactura & 12 \\
\hline & & Indeterminado & 2 \\
\hline & & Punta semiacanalada & 4 \\
\hline & Metatarso & Punta plana & 1 \\
\hline Ozotoceros & & Indeterminado & 1 \\
\hline \multirow[t]{3}{*}{ bezoarticus } & Metacarpo & Punta semiacanalada & 1 \\
\hline & Asta & Punta cónica & 1 \\
\hline & & Indeterminado & 2 \\
\hline \multirow[t]{2}{*}{ cf. Mazama sp. } & Asta & Punta semiacanalada & 1 \\
\hline & & Punta cónica & 4 \\
\hline \multirow[t]{4}{*}{ Cervidae } & Asta & Punta semiacanalada & 1 \\
\hline & & Preforma & 1 \\
\hline & & Indeterminado & 2 \\
\hline & Hueso largo & Punta semiacanalada & 1 \\
\hline \multirow[t]{2}{*}{ Mamífero } & & Bipunta & 1 \\
\hline & Indeterminado & Indeterminado & 4 \\
\hline Siluriformes & Espina & Indeterminado & 3 \\
\hline
\end{tabular}




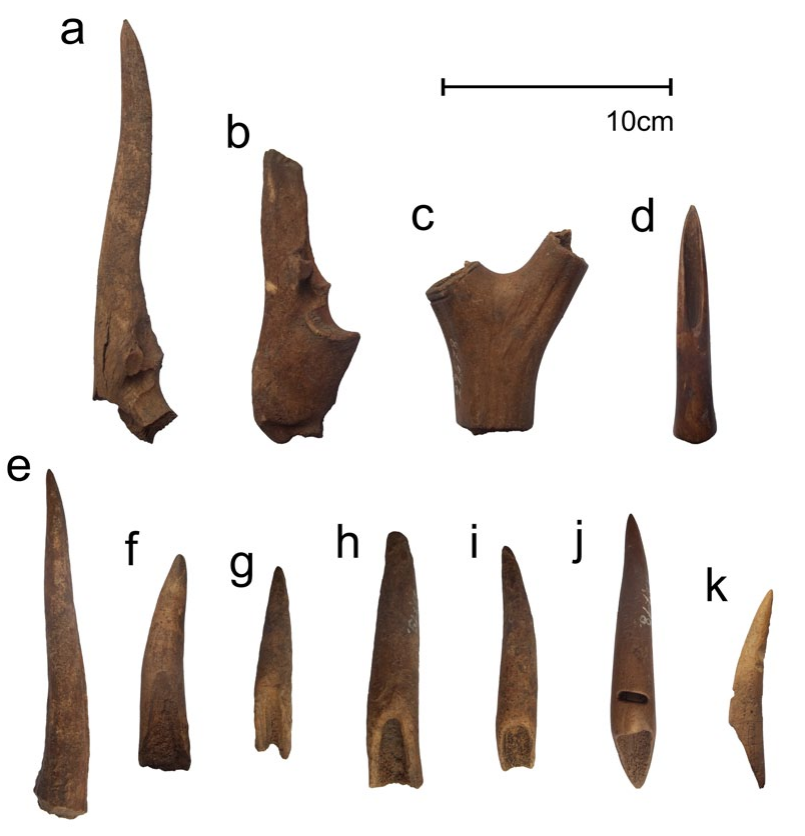

Figura 5. Artefactos óseos: punta plana con epífisis (a) y bisel (b) elaborados sobre cúbito de Blastocerus dichotomus; desecho de manufactura sobre asta de Blastocerus dichotomus (c); punta semiacanalada sobre metatarso de Ozotoceros bezoarticus (d); puntas cónicas (cabezales de arpón) sobre asta de Blastocerus dichotomus en diferentes estadios del proceso de manufactura (e-j); punta cónica sobre asta de Cervidae con incisiones geométricas ( $\mathrm{k}$ ).

Figure 5. Bone tools: Epiphyseal based flat point (a) and bevel (b) made on Blastocerus dichotomus ulnas; Blastocerus dichotomus antler manufacture debris (c); half-fluted point made on Ozotoceros bezoarticus metatarsal (d); harpoon heads made on Blastocerus dichotomus antler in different stages of manufacture $(e-j)$; harpoon head with geometric incisions made on Cervidae antler ( $k$ ).

desarticulación y descarne. En Myocastor coypus se registraron numerosas huellas de corte $(n=33)$ en distintos sectores de las hemimandíbulas (rama ascendente, fosa masetérica, proceso coronoides, diastema y cuerpo mandibular), así como alrededor del cuello y en la diáfisis del fémur (4) y sobre la diáfisis distal de la tibia $(n=1)$. En cuanto a Hydrochoerus hydrochaeris, las huellas de corte se localizan en la diáfisis del fémur $(n=2)$, tibia $(n=1)$, radio $(n=1)$ y ulna $(n=1)$, así como en la hemipelvis $(n=1)$, rótula $(n=1)$ y vértebras $(n=2)$.

A excepción de los mustélidos, todas las especies de carnívoros identificadas en el sitio muestran un patrón común de distribución de marcas de origen antrópico a lo largo de las hemimandíbulas y la región anterior del cráneo. Todas las hemimandíbulas asignadas a Cerdocyon thous $(n=6)$, Oncifelis geoffroyi $(n=4)$, Lynchailurus pajeros $(n=2)$, Herpailurus yagouaroundi $(n=1)$ y Felidae indeterminado $(n=1)$ presentan numerosas huellas de corte. En la rama horizontal, estas consisten en estriaciones transversales ubicadas a lo largo del borde inferior de la hemimandíbula y transversales y oblicuas en la porción anterior de la cara lateral. En la porción posterior de la hemimandíbula son recurrentes en los procesos coronoides, condilar y, en menor medida,

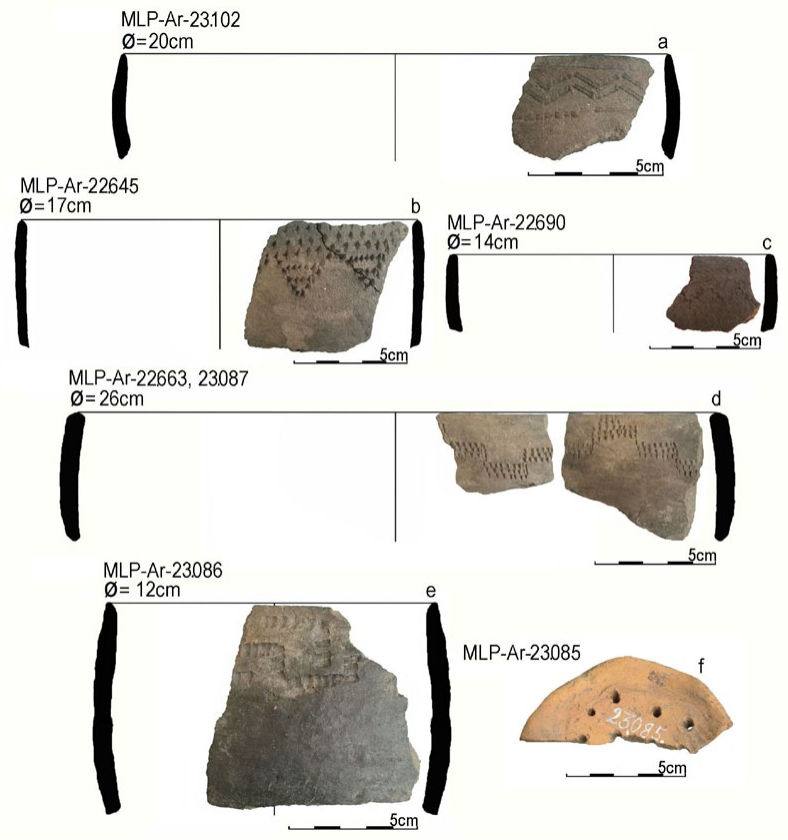

Figura 6. Contornos de los bordes incluidos en el NMV y pieza perforada.

Figure 6. Profiles of rim sherds included in the NMV and perforated piece.

angular. Varios cráneos y fragmentos craneales asignados a Cerdocyon thous $(n=3)$, Chrysocyon brachyurus $(n=2)$, Oncifelis geoffroyi $(n=1)$ y Herpailurus yagouaroundi $(n=1)$ presentan huellas de corte sobre la porción anterior del arco cigomático y a lo largo de los frontales, nasales, maxilares y premaxilares. Estas marcas, junto con las ubicadas en la porción anterior de las hemimandíbulas, pueden atribuirse a actividades de cuereo, mientras que las localizadas en la porción posterior de este último elemento se asocian a operaciones de desarticulación y/o descarne. En el caso de los mustélidos, las huellas de corte se registraron únicamente sobre elementos del poscráneo de Lontra longicaudis $(n=2)$, sobre la diáfisis de un húmero y un cúbito.

Por último, se detectaron también huellas de corte sobre espinas pectorales y dorsales de armados $(n=6)$. Estas se ubican principalmente en la porción proximal de la rama de la espina, cerca de la región articular, por lo que es posible suponer que se relacionen con la remoción de este elemento.

En cuanto a los patrones de fractura, se registraron numerosos huesos largos fracturados asignados a Blastocerus dichotomus $(n=48)$, Hydrochoerus hydrochaeris $(n=3)$, Artiodactyla $(n=12)$ y mamífero grande indeterminado $(n=101)$. A partir del análisis de la forma, el ángulo de fractura y la textura del borde, se calculó un IFF de 2,5, valor consistente con un conjunto generado principalmente por fractura de huesos en estado fresco y compatible con la explotación de la médula. Adicionalmente, varios especímenes $(n=33)$ 


\begin{tabular}{ccccc}
\hline \multicolumn{2}{c}{ Atributos tecnomorfológicos } & $\mathrm{n}$ & $\mathrm{NMV}$ & $\mathrm{SE}$ \\
\hline \multirow{2}{*}{ Dirección del } & recto & $25: 35$ & - & - \\
borde & levemente evertido & $5: 35$ & - & - \\
& levemente invertido & $5: 35$ & - & - \\
& indeterminado & - & - & - \\
Forma del labio & plano & $6: 35$ & - & - \\
& redondeado & $7: 35$ & - & - \\
Diámetro de & biselado & $21: 35$ & - & - \\
boca y tamaño & indeterminado & $1: 35$ & - & - \\
& 11 cm (pequeño) & $4: 35$ & - & - \\
Tratamiento de & $19-40$ cm (grande) & $20: 35$ & - & - \\
superficie & indeterminado & $5: 35$ & - & - \\
& alisado irregular & - & - & - \\
\hline & alisado & - & $19: 35$ & $23: 35$ \\
& pulido & - & $14: 35$ & - \\
\hline
\end{tabular}

Tabla 5. Características tecnomorfológicas de los bordes incluidos en el NMV. Referencias: SE: superficie externa; SI: superficie interna.

Table 5. Techno-morphological characteristics of rim sherds included in the NMV. References: SE: external surface; SI: internal surface.

presentaron escotaduras y negativos de lascados. Finalmente, se registraron escasos especímenes óseos termoalterados $(n=9)$, correspondientes principalmente a astrágalos y fragmentos de huesos largos de Blastocerus dichotomus. Sin embargo, la elevada proporción de depositación de óxido de manganeso en muchos casos imposibilitó relevar este atributo.

\section{Artefactos óseos}

Se registraron 59 restos óseos con evidencias tecnológicas, que incluyen 12 desechos de manufactura, 11 preformas, 22 instrumentos y 14 fragmentos que no pudieron asignarse a ninguna de estas categorías (Tabla 4). La mayor parte de este conjunto fue elaborado sobre unidades anatómicas de cérvidos (84,7\%), principalmente Blastocerus dichotomus $(n=31)$, seguido de Ozotoceros bezoarticus ( $n=10)$ y cf. Mazama sp. $(n=1)$, mientras que otros restos de cérvidos no pudieron ser determinados $(n=8)$. En el caso de Blastocerus dichotomus se elaboraron instrumentos sobre cúbitos y astas. Los cúbitos fueron seccionados transversalmente y sus extremos proximales se utilizaron para elaborar puntas planas con epífisis $(\mathrm{n}=2)$ (Figura 5 a) y un bisel (Figura 5 b). Los instrumentos sobre

\begin{tabular}{cccc} 
Esquema & Código & Tiestos (NMV) & Recurso técnico \\
\hline inciso de línea llena \\
inciso de punto simple \\
inciso de línea llena \\
inciso de línea llena
\end{tabular}

Tabla 6. Elementos de diseño diferenciados en la cerámica del TIIBL.

Table 6. Design elements distinguished in TIIBL. asta consisten principalmente en puntas cónicas $(n=3)$, comúnmente interpretadas como cabezales de arpones (e.g. Bonomo et al. 2009; Pérez Jimeno y Buc 2010). Además, se registró una horqueta que presenta en la zona de bifurcación del asta perforaciones sobre ambas caras (una sin terminar), elaboradas por rotación circular. Entre los restos de asta de Blastocerus dichotomus se detectaron numerosos desechos $(n=12)$ y preformas $(n=10)$, a partir de los cuales se pudieron reconocer los diferentes estadios del proceso de manufactura de los cabezales de arpón, parte de los cuales fueron propuestos anteriormente para las puntas cónicas sobre astas de cérvidos en general (Bonomo et al. 2009). Las astas fueron seccionadas transversalmente a diferentes niveles y los extremos distales se seleccionaron para su posterior formatización. Este procedimiento se evidencia a partir de los numerosos desechos de manufactura (Figura 5 c) y preformas (Figura 5 e) con evidencias de aserrado perimetral. Posteriormente, el extremo proximal fue percutido, generando un negativo de lascado sobre la cara superior de la pieza (Figura 5 f). Esto es seguido por la remoción del tejido esponjoso (ahuecado) y la formatización del borde de fractura mediante raspado (Figura 5 g y h). Luego, se realizó la configuración general de la pieza mediante un raspado intenso de la superficie (Figura 5 i) con el objetivo de hacerla más simétrica y recta y terminar de formatizar el diente. Finalmente, se emparejó su superficie mediante abrasión y pulido cada vez más fino y se realizó la perforación en la base de la punta (Figura 5 j).

Se registraron también puntas cónicas sobre astas asignadas a Ozotoceros bezoarticus y a cérvido indeterminado, una de las cuales está decorada mediante incisiones (elemento decorativo B2 sensu Bonomo 2013) (Figura 5 k). Además de las astas, se seleccionaron los metapodios de venado como soportes para elaborar, a partir de sus porciones proximales, puntas semiacanaladas ahuecadas $(n=5)$ (Figura 5 d) y una punta plana. Es interesante destacar que no se registraron preformas ni desechos de manufactura que denoten la manufactura in situ de artefactos sobre unidades anatómicas de esta especie. En cuanto a cf. Mazama sp., se registró únicamente una punta semiacanalada elaborada sobre asta. Además, se registró una punta semiacanalada y una bipunta elaboradas sobre huesos largos de mamíferos indeterminados. Por último, algunas espinas de Siluriformes $(n=3)$, presentan evidencias de raspado/ abrasión y pulido y eliminación del dentado, pero, debido a su estado fragmentario, no pudieron asignarse a un grupo morfológico.

\section{Alfarería}

El conjunto cerámico está integrado por 392 tiestos, correspondientes a cuerpos $(n=350)$ y bordes $(n=42)$ de diversos recipientes. Se reconocieron nueve masas de arcilla sin claras evidencias de cocción, de las cuales dos exhiben improntas de ramas y una, posibles huellas de 
Tabla 7. Características tecnológico-morfo-funcionales de los artefactos picados y/o abradidos. Referencias: Oq-Sup= oquedades o superficies activas; Indet.= indeterminado; //= reciclaje; $E=$ entero; $F>3 / 4=$ fragmento mayor a 3/4 de la pieza completa; $F<1 / 2=$ fragmento menor a la mitad de la pieza completa; $\mathrm{F}$ ind= fragmento indeterminado.

Table 7. Techno-morpho-functional characteristics of ground tools. References: Oq-Sup= holesor active surfaces; Indet. = Undetermined; //= recycling; $E=$ complete; $F>3 / 4=$ more than $3 / 4$ of the piece is complete; $F<1 / 2=$ less than half of the piece is complete; $F$ ind $=$ undetermined fragment.

\begin{tabular}{|c|c|c|c|c|c|c|c|}
\hline $\begin{array}{l}\text { Tipo artefacto } n^{\circ} \text { y } \\
\text { función }\end{array}$ & $\begin{array}{c}\mathrm{N}^{\circ} \\
\text { pieza }\end{array}$ & $\begin{array}{l}\text { Materia } \\
\text { prima }\end{array}$ & $\begin{array}{c}\text { Esta- } \\
\text { do }\end{array}$ & $\begin{array}{l}\mathrm{N}^{\circ} \mathrm{Oq}^{-} \\
\text {Sup }\end{array}$ & $\begin{array}{c}\text { Grupo } \\
\text { Tipológico }\end{array}$ & $\begin{array}{c}\text { Desgaste por } \\
\text { uso }\end{array}$ & Totales \\
\hline \multirow{2}{*}{ Simple } & 24085 & Granito & $F>1 / 2$ & 01 & yunque & fuerte & \multirow{5}{*}{3} \\
\hline & 24106 & Indet. & E & 01 & yunque & fuerte & \\
\hline \multirow{3}{*}{$\begin{array}{l}\text { Compuesto// } \\
\text { Simple }\end{array}$} & \multirow{3}{*}{24098} & \multirow{3}{*}{ Indet. } & \multirow{3}{*}{$F<1 / 2$} & s1 & Indet. & agotado & \\
\hline & & & & $\mathrm{O} 2$ & yunque & agotado & \\
\hline & & & & s3 & percutor & moderado & \\
\hline \multirow[t]{5}{*}{ Doble } & \multirow[t]{2}{*}{24082} & \multirow[t]{2}{*}{ Indet. } & \multirow[t]{2}{*}{$F>3 / 4$} & $\begin{array}{l}\text { s1 } \\
\text { s2 }\end{array}$ & $\begin{array}{l}\text { percutor } \\
\text { percutor }\end{array}$ & $\begin{array}{l}\text { moderado } \\
\text { moderado }\end{array}$ & \multirow[t]{2}{*}{1} \\
\hline & & & & s1 & mano mortero & agotado & \\
\hline & 24083 & Indet. & $F>3 / 4$ & o2 & yunque & leve & \multirow{11}{*}{4} \\
\hline & & & & o3 & yunque & leve & \\
\hline & \multirow{4}{*}{24097} & \multirow{4}{*}{ Arenisca } & \multirow{4}{*}{$F>1 / 2$} & 01 & pasivo indef. & agotado & \\
\hline \multirow{10}{*}{ Compuesto } & & & & O2 & yunque & moderado & \\
\hline & & & & O3 & yunque & leve & \\
\hline & & & & 04 & yunque & leve & \\
\hline & \multirow{3}{*}{24099} & \multirow{3}{*}{ Cuarcita } & \multirow{3}{*}{$E$} & s1 & abradidor & fuerte & \\
\hline & & & & s2 & mano mortero & moderado & \\
\hline & & & & 01 & yunque & leve & \\
\hline & \multirow[t]{2}{*}{24100} & \multirow[t]{2}{*}{ Indet. } & \multirow[t]{2}{*}{$F>3 / 4$} & s2 & percutor & leve & \\
\hline & & & & s3 & percutor & leve & \\
\hline & 24084 & Indet. & $F$ ind & - & - & - & \multirow{5}{*}{5} \\
\hline & 24087 & Indet. & $F$ ind & - & - & - & \\
\hline \multirow[t]{3}{*}{ Indet. } & 24090 & Granito & $F$ ind & - & - & - & \\
\hline & 24105 & Indet. & $F$ ind & - & - & - & \\
\hline & 24109 & Indet. & $F$ ind & - & - & - & \\
\hline
\end{tabular}

amasado. Además, se registró una pieza fracturada de forma semicircular, con varias perforaciones realizadas antes de la cocción, cuya forma completa no fue posible determinar (Figura $6 \mathrm{f}$ ).

Se estimó un número mínimo de 35 vasijas, a partir de la cuantificación de aquellos bordes con atributos que permitieran distinguirlos entre sí (Figura 6). Se realizaron cuatro remontajes que agrupan dos fragmentos cada uno; tres de ellos corresponden a posibles bases convexas (no pudieron asociarse a ninguna de las vasijas identificadas) y el restante, a un borde incluido en el NMV. A pesar de la fragmentación del conjunto, se infirieron formas abiertas de contornos simples, en algunos casos correspondientes a posibles cuencos (Figura $6 \mathrm{~d}$ y e), con paredes de 5-6 $\mathrm{mm}$ de espesor, principalmente rectas, y labios biselados (Tabla 5). Predominan las vasijas de tamaño mediano, con diámetros de boca comprendidos entre 12 y $18 \mathrm{~cm}$. Tres de los bordes presentan perforaciones de suspensión de forma subcónica $(n=2)$ y subcircular $(n=2)$, con diámetros que varían entre 5 y $9 \mathrm{~mm}$, ubicadas a 7-15 $\mathrm{mm}$ de los labios.

La técnica de superposición de rollos de arcilla se reconoció en las superficies internas de diez piezas; en siete se aplicó, al menos, en el borde y el cuerpo inmediatamente adyacente, mientras que en las restantes tres fue utilizada en la elaboración del labio. Entre los tratamientos aplicados luego del levantado, predominan el alisado en las superficies externas y el alisado irregular en las caras internas (Tabla 5). La mayoría de los bordes $(n=32)$ exhibe marcas de la acción de alisar (e.g. surcos alternados paralelos y entrecruzados, de diferente profundidad). Estas huellas se registraron en las dos superficies de 17 piezas y en las caras internas de 15 .

Se aplicaron variantes del inciso en las superficies externas del borde y cuerpo adyacente de 27 vasijas (dos de ellas exhiben, además, incisiones en el labio). Se registró el predominio del inciso de punto simple $(n=11$, Figura $6 \mathrm{~b}$ y d) y, en menor proporción, de línea llena ( $n=9$, Figura 6 c) y surco rítmico ( $n=6$, Figura 6 a y e). En un solo tiesto se reconocieron dos variantes del inciso (de surco rítmico y línea llena). En dos fragmentos posiblemente se aplicó pigmento rojo.

Las representaciones decorativas fueron realizadas mediante los tipos de inciso mencionados y se analizaron de acuerdo con la clasificación de Di Prado (2015) para los repertorios decorativos de la alfarería del centro-este de Argentina. Se diferenciaron nueve elementos de diseño (Tabla 6) mediante la comparación de las piezas de la 


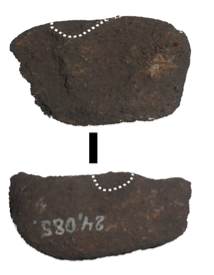

24085 a

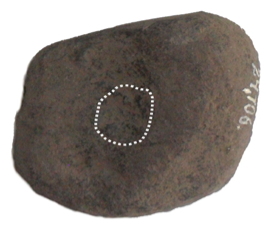

24106

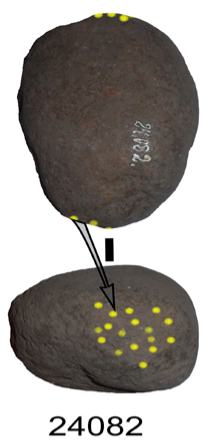

24082

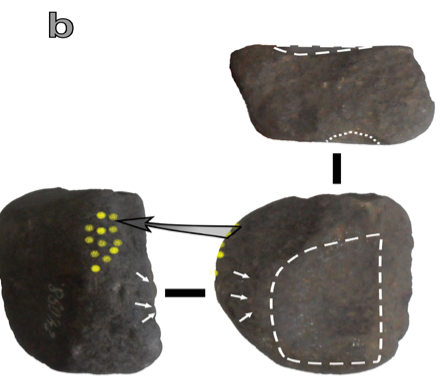

24098

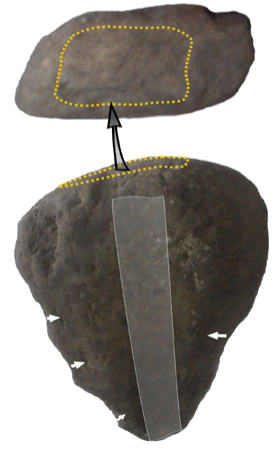

24099

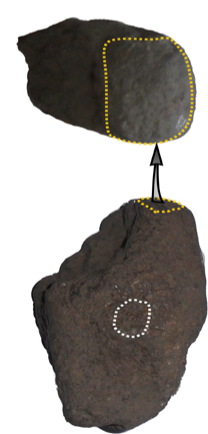

24083

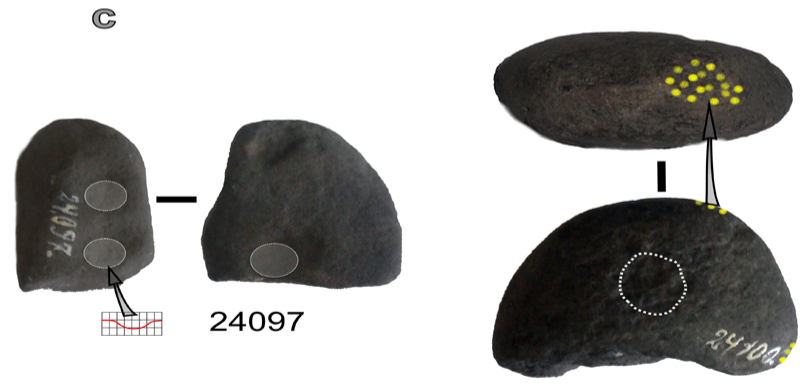

24100

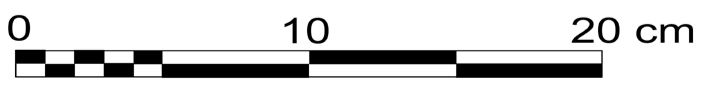

Figura 7. Artefactos picados y/o abradidos: yunques (a); percutores (b); artefactos compuestos (c).

Figure 7. Ground tools: anvils (a); hammers (b); compound artefacts (c).

muestra bajo estudio entre sí y con repertorios decorativos del Delta Inferior del Paraná y el noreste de la provincia de Buenos Aires (Caggiano 1979; Kusch y Conlazo 1984; Loponte y Pérez 2013; Rodrigué 2005; Serrano 1972). Algunos elementos no pudieron ser identificados debido a la fragmentación de las piezas.

Entre las unidades de diseño identificadas se encuentran variantes de la línea en zigzag, plasmadas mediante inciso de punto simple (E3d) y línea llena (E3C, E3e). La distinción entre las dos últimas unidades se realizó en base a las diferencias en el trazo de las incisiones, que en el caso del E3c son rectas mientras que en el E3e consisten en líneas con pequeñas ondulaciones (festoneadas). Estas últimas también fueron empleadas para plasmar el E4a. En un caso, el E3e y el E4a aparecen asociados en un mismo fragmento y el trazo que los conforma muestra poca profundidad y rebaba (Figura $6 \mathrm{c}$ ). Esta última característica indica que las representaciones se efectuaron cuando la pasta se encontraba en estado plástico.

Interesa destacar los elementos de diseño E22 y E22a que consisten en áreas rellenas de puntos no delimitadas por líneas llenas (Figura 6 b y d). En la muestra bajo estudio fueron registrados en tres vasijas y en otras dos su presencia es dudosa debido a la fragmentación. También se reconocieron elementos de diseño realizados con surco rítmico, tales como el E23 y E24, y posibles áreas rellenas con elementos plasmados con la misma técnica, cuya descripción quedó incompleta por la fragmentación.

Entre las alteraciones generadas por el uso, se registraron restos de hollín y ennegrecimiento producto de la exposición al fuego en las superficies externas de ocho bordes. Por otra parte, se identificaron desprendimientos o esquirlas en los labios de once tiestos, que podrían haberse generado por acciones culinarias (e.g. revolver) o por el modo en que fueron manipuladas las vasijas (e.g. dispuestas boca abajo) (Vieugué 2014: 627).

\section{Análisis del material lítico}

Se registraron 28 artefactos líticos entre los que se identificaron 13 artefactos picados y/o abradidos, 1 artefacto tallado, 2 productos de talla y 12 ecofactos. Los artefactos picados y/o abradidos están en su mayoría fracturados e incluyen artefactos compuestos $(n=4)$, yunques $(n=2)$, percutores $(n=2)$ y artefactos indeterminados $(n=5)$. Se destaca el registro de grupos tipológicos de molienda y de oquedades de yunque entre los artefactos compuestos (Tabla 7).

En los yunques (MLP-Ar-24085 y 24106) se utilizaron nódulos de granito $(600 \mathrm{~g})$ y de materia prima indeterminada (100 g) que no habrían sido modificados previo al uso (Figura 7 a). Estos son artefactos simples 
con condiciones diferentes al momento del descarte: la pieza MLP-Ar-24106 presenta remanente de vida útil, mientras que la MLP-Ar-24085 es una pieza agotada. Asimismo, se identificaron oquedades de yunque entre los artefactos compuestos.

Los percutores comprenden, por un lado, un artefacto doble (MLP-Ar-24082) sobre un nódulo espeso de materia prima indeterminada de unos $550 \mathrm{~g}$ sin rastros de manufactura previa al uso. Por otro lado, el percutor MLP-Ar-24098 es producto del reciclaje de un artefacto indeterminado/yunque fracturado, en el que fue posible reconocer el uso de un nódulo facetado como forma-base primaria. Esta última pieza pesa $420 \mathrm{~g}$, y presenta lascados y picado sobre las caras laterales. La superposición con los rastros de uso del percutor permite proponer que la manufactura corresponde a la formatización del artefacto indefinido (Figura 7 b). En ambos percutores los rastros de uso se ubican sobre los bordes de las piezas y fueron descartados con remanente de vida útil.

En los artefactos compuestos se combinan superficies de mano mortero con yunque (MLP-Ar-24083) o abradidor (MLP-Ar-24099), u oquedades de yunque con superficies de percutor (MLP-Ar-24100) y de pasivo indefinido (MLP-Ar-24097). Las formas-base seleccionadas incluyen nódulos tabulares de cuarcita y arenisca para la mano de mortero/abradidor y el pasivo indefinido/yunque, y un nódulo facetado de materia prima indeterminada para la mano de mortero/yunque. En el yunque/ percutor no se determinó la forma-base debido al grado de fragmentación que presenta. Las evidencias de manufactura entre los artefactos compuestos se limitan a lascados sobre parte del contorno de la mano de mortero/abradidor (Figura $7 \mathrm{c}$ ), que se asociaría a la zona de prensión de este artefacto durante el uso como mano de mortero.

Entre las oquedades de yunque, tanto de artefactos compuestos como de los yunques simples, se distinguieron variantes en cuanto al desgaste por uso (véase Tabla 7). En el caso de las oquedades del yunque MLP-Ar-24097, presentan sección perpendicular a la oquedad de tipo circular, unos $20 \mathrm{~mm}$ de diámetro y presentan redondeo como rastros de uso (Figura 7 c). Las restantes oquedades de yunque presentan sección perpendicular irregular o circular irregular, diámetros variables (entre 20 y $40 \mathrm{~mm}$ ) y microlascados-machacados como rastros de uso. En otras colecciones analizadas del Delta Inferior del Paraná - Túmulo I del Brazo Gutiérrez, Túmulo I del Brazo Largo, Túmulo II del Paraná Guazú (véase Bonomo et al. 2009)se observaron diferencias similares entre los yunques. Es posible que correspondan a variaciones en las clases de objetos a fracturar (e.g. frutos, semillas, raíces, huesos u otros artefactos líticos) sobre sus superficies (Bonomo et al. 2009 y bibliografía allí citada).

Interesa destacar los rastros de uso particulares de la superficie activa de abradidor del artefacto compuesto MLP-Ar-24099 (Figura 7 c). En primer lugar, el área con alisado, pulido y estrías paralelas se dispone en posición oblicua sobre la cara. La sección paralela al largo de esta zona es de tipo plano inclinado y la paralela al ancho es de tipo hemielipsoide. Presenta curvatura transversal cóncava moderada, una profundidad de $3 \mathrm{~mm}$ y un ancho máximo de $22 \mathrm{~mm}$. Estos caracteres morfológicos permiten incluir a esta superficie activa dentro del subgrupo tipológico de abradidor con surco en "U" (abraders with U-shaped grooves) caracterizados por Adams (2002). Como puntualiza esta autora, la textura de estos artefactos define si las superficies sobre las que se utilicen serán alisadas, pulidas o bruñidas. En este caso, el tamaño medio de los granos de esta cuarcita podría alisar las superficies dejando un acabado rugoso de las mismas.

Las superficies usadas como mano de mortero presentan rastros de uso que indican movimientos de presión vertical y de percusión sobre el artefacto pasivo. En cuanto al desgaste por uso, en un caso es moderado (MLP-Ar-24099), mientras que en el otro (MLP-Ar-24083) la mayor parte de la zona activa fue eliminada debido a la fractura que presenta este artefacto, por lo que el uso como mano de mortero estaría agotado.

Los artefactos indeterminados (MLP-Ar-24084, 24087, $24090,24105,24109$ ) incluyen fragmentos que pesan entre 130 y $830 \mathrm{~g}$. En estas piezas no se observaron rastros de uso, pero presentan evidencias de formatización por picado (MLP-Ar-24087), por picado-alisado-pulido (MLPAr-24084, 24090 y 24105) o por picado-alisado-pulidobruñido (MLP-Ar-24109) sobre caras y/o bordes.

En la muestra se detectaron escasos artefactos manufacturados por talla. El único instrumento corresponde a un artefacto de formatización sumaria (MLP-Ar-24104) de tamaño grande y módulo de longitudanchura mediano normal, confeccionado a partir de un nódulo facetado. Las otras dos piezas comprenden lascas fracturadas sin talón de materia prima indeterminada (MLP-Ar-24110 y 24103) de 15 y 5 cm de largo respectivamente. Estos artefactos son productos de la talla de nódulos (lascas primarias), como lo atestiguan los restos de corteza remanentes sobre la cara dorsal.

El conjunto de materiales líticos se completa con siete rodados enteros (MLP-Ar-24086, 24091, 24094, 24101, $24108 \mathrm{y} \mathrm{s} / \mathrm{n}^{\circ}$ ) y cinco fracturados (MLP-Ar-24089, 24092, 24095, 24096, 24102 y 24107) en los que no se observaron modificaciones antrópicas. Estas piezas comparten caracteres morfológicos (tipo de forma base, dimensiones absolutas y relativas, peso) con gran parte de los artefactos picados/abradidos descriptos previamente. Representan nódulos espesos, chatos, facetados y tabulares de rocas no determinadas cuya procedencia es probablemente la costa del río Uruguay (Kröhling 2009; Veroslavsky y Ubilla 2007). Los nódulos 
enteros tienen entre 8,7 y 7,3 cm de largo máximo. Si bien el peso promedio de las piezas enteras es de $150 \mathrm{~g}$, dos fragmentos (MLP-Ar-24092 y MLP-Ar-24089), que representan más de la mitad del ecofacto original, superan este valor con 200 y $570 \mathrm{~g}$.

\section{Discusión}

En principio, hay que tener en cuenta que se analizó una colección histórica excavada hace más de 90 años y que existe un sesgo doble: uno derivado de las técnicas de excavación expeditivas de la época y otro, de la posible pérdida de materiales en los depósitos. Además, el uso de pala y la ausencia de tamizado del sedimento durante la excavación del montículo probablemente implicaron la pérdida de gran parte de los huesos más pequeños (sobre todo peces y micromamíferos). Sin embargo, la riqueza de la colección y de la información asociada justifica el análisis llevado a cabo.

Los principales taxones representados en la colección son el ciervo de los pantanos, seguido del coipo y, en menor medida, el carpincho y los peces. En términos generales, estos recursos faunísticos son similares a los registrados en otros sitios del Delta Inferior del río Paraná, tanto en el sector continental como en el insular (e.g. Acosta 2005; Acosta et al. 2013; Caggiano 1984; Loponte et al. 2012; Salemme y Tonni 1983) e indican una subsistencia orientada a la explotación de especies propias de estos ambientes fluviolacustres. Al igual que en otros sitios del sector de islas del Delta Inferior, Ozotoceros bezoarticus, que habita típicamente los ambientes de llanura abierta, se encuentra escasamente representado y pudo haber ingresado al sitio sólo como parte del instrumental óseo conservado. Por otra parte, al considerar la representación taxonómica relativa, TIIBL presenta una menor proporción de peces y de roedores pequeños y medianos en comparación con otros sitios del área, donde estos taxones suelen dominar a los cérvidos en términos de NISP\% (e.g. Acosta 2005; Acosta et al. 2013). Posiblemente, estas diferencias puedan atribuirse a los sesgos de muestreo anteriormente señalados, aunque no habría que descartar diferencias vinculadas con la función de los sitios, la estacionalidad de la ocupación o las prácticas culturales.

Las evidencias de procesamiento sobre ciervo de los pantanos indican una secuencia de desollado, desarticulación de los miembros y la mandíbula, fileteo y fractura de huesos largos. En el caso de los roedores, Myocastor coypus también presenta evidencias de cuereo, desarticulación y descarne. Una particularidad interesante del conjunto arqueofaunístico es la presencia de claras evidencias de procesamiento y consumo de Hydrochoerus hydrochaeris (huellas de corte compatibles con operaciones de desarticulación y descarne y fracturas frescas). Este taxón es poco frecuente en otros sitios del área, lo que ha llevado a plantear (e.g. Acosta 2005;
Salemme y Tonni 1983) que habría una excepción de consumo para el área Norte de la región pampeana y el Delta Inferior del Paraná. Las evidencias del TIIBL sugieren que este recurso habría sido consumido, al menos en algunas ocasiones y/o que existirían diferencias espaciales en su aprovechamiento entre los distintos sectores del Delta Inferior (continental e insular).

Otro de los aspectos interesantes de la colección es el numeroso y variado conjunto de artefactos óseos que presenta. Los grupos morfológicos representados entre los instrumentos son similares a los registrados en otros sitios del Delta Inferior del Paraná (Bonomo 2013; Bonomo et al. 2009; Pérez Jimeno y Buc 2010). Mientras que la presencia de desechos de manufactura y preformas sobre astas de ciervo de los pantanos permite proponer la manufactura in situ de cabezales de arpón, es probable que los instrumentos elaborados a partir de unidades anatómicas de venado hayan ingresado al sitio ya terminados o en estadios finales del proceso de manufactura. Por otra parte, el abradidor lítico con surco en "U" (MLP-Ar-24099) podría haber estado involucrado en la elaboración de instrumentos de hueso o en el trabajo de varas para fabricar astiles de madera para flechas (Matarrese 2015; Prous y Alonso 2010; Silvestre y Buc 2015).

Uno de los aspectos más destacables de la colección es la gran abundancia y diversidad taxonómica de carnívoros, que es mayor a la registrada en otros sitios del Delta Inferior del río Paraná. La colección incluye varias especies que no han sido identificadas en otros sitios arqueológicos del área: Cerdocyon thous ${ }^{2}$, Oncifelis geoffroyi, Lynchailurus pajeros y Herpailurus yagouaroundi. Además, los cráneos y mandíbulas de cánidos y félidos muestran huellas antrópicas de acuerdo a un patrón muy recurrente, que es similar a lo descrito por Mallye (2011) para el desollado experimental de pequeños carnívoros. De acuerdo con este autor, las huellas de cuereo presentan una distribución muy conspicua en los cráneos (se concentran en la región frontal y alrededor del morro) y en la porción anterior de la hemimandíbula. Este patrón es muy claro entre los restos de carnívoros de la colección y sugiere una intensa actividad peletera sobre distintas especies de cánidos y félidos. Además de este tipo de huellas, se registraron marcas ubicadas detrás de la fosa masetérica, que podrían corresponder a actividades de descarne y/o desarticulación.

La evidencia arqueológica en relación con la obtención de pieles de carnívoros es compatible con los datos etnohistóricos de principios del S. XVI. Particularmente relevante es el diario de Lopes de Souza quien, para el área del Delta Inferior, relata el encuentro con cuatro indígenas chana mbeguá quienes "... traziam na cabeça

\footnotetext{
2 En relación con este zorro, Acosta y colaboradores (2015) registran piezas dentales de cánidos que podrían corresponder tanto a Cerdocyon thous como a Lycalopex gymnocercus.
} 
hûsbarretes [birretes] das pelles das cabeças das onças, com os dentes e com tudo" (Lopes de Souza [1530-1532] 1839: 48). Asimismo, el relato "Nova Gazeta da Terra do Brasil", (Schuller 1915), que posiblemente refiera a la expedición de João de Lisboa y Estêvão Fróis al Río de La Plata en 1515 (Relaño 2005), describe el uso de pieles de diferentes felinos (comparables con los leones, leopardos, linces y ginetas del Viejo Mundo).

En términos arqueológicos, la importancia de los carnívoros en el universo simbólico de los grupos del Delta Inferior del Paraná se refleja también en la presencia de cráneos y mandíbulas de distintas especies de cánidos y félidos en contextos funerarios: Panthera onca en los sitios Río Luján (Petrocelli 1975), Don Santiago (Caggiano 1984:25) y BD-S2, Isla Talavera (Caggiano et al. 2003); Dusicyon avus en Río Luján (Prevosti et al. 2004) y Chrysocyon brachyurus en Brazo Largo (Gatto 1939). Asimismo, en varios sitios del Delta Inferior se han recuperado objetos ornamentales elaborados sobre dientes asignados a Panthera onca, Puma concolor, Lontra longicaudis, Nasua nasua, Chrysocyon brachyurus, Canis familiaris y zorros indeterminados (Acosta et al. 2015). Los elementos craneales (cráneos, mandíbulas y piezas dentales) de cánidos y félidos fueron seleccionados dentro del universo natural para ser enterrados junto a los cuerpos humanos, lo cual implica conductas de índole ritual que a su vez señalan que los carnívoros ocupaban un lugar privilegiado en el sistema de creencias de estas sociedades prehispánicas (Bonomo 2006). Por último, se debe mencionar el hallazgo de un perro en un entierro en el sitio Cerro Lutz (Acosta et al. 2011). Al tratarse de un animal doméstico, podría estar operando de una manera distinta a la de las especies silvestres lo que requiere explicaciones más complejas (véase Prates 2014).

En muchas sociedades de las tierras bajas tropicales de América del Sur (por ejemplo los Héta, Kozák et al. 1979), el uso de pieles de carnívoros silvestres, especialmente de félidos, se relaciona con su valor apotropaico o como expresión metonímica de espíritus poderosos o protectores. En el caso del Delta Inferior del Paraná, el uso de estas pieles, incluyendo la exhibición de las fauces de grandes félidos (como se desprende del diario de Lopes de Souza) muestra a estos animales como referentes simbólicos importantes y/o manifestaciones de una ontología en la cual estas especies podrían ser una extensión del ser (self) o la representación de un estado en un proceso de transformación de humanos/animales.

En relación con la alfarería, conjuntos con predominio de formas abiertas, de tamaño mediano, paredes rectas, espesores de 5-6 $\mathrm{mm}$ y bases convexas han sido descriptos por otros autores para el Delta Inferior del río Paraná (Caggiano 1979: 110-113; Lothrop 1932: 153), quienes también se han referido a la escasez de formas restringidas. Aunque fracturada y de pequeño tamaño, también la pieza perforada (Figura 6 f), es similar a un objeto hallado en El Cerrillo (Lothrop 1932: 154). Este último, que posee más de 20 perforaciones, pudo haber formado parte de un colador (Bonomo 2013) o bien de un steaming dish (disco para cocinar al vapor) que fue descripto por Nordenskiöld (véase cita en Lothrop 1932: 153).

Las tendencias relacionadas con las variantes del inciso y los elementos de diseño representados también se ajustan a las referidas por otros autores para el Delta Inferior del Paraná (Caggiano 1979: 111; Loponte y Pérez 2013: 15-19; Rodrigué 2005; Serrano 1972: 22-25). Repertorios decorativos semejantes han sido incluidos en los tipos Ibicuy punteado e Ibicuy inciso de la Facie Ibicuy de la Cultura Entrerriana (Serrano 1972: 22-25). Más precisamente, el E22 ha sido reconocido también en La Bellaca 2- denominado áreas punteadas por Rodrigué (2005: 68)- y en el Túmulo I del Brazo Largo (Caggiano 1979: 115-116), mientras que el E3e y E4a están presentes en El Cerrillo (Lothrop 1932: 155), Túmulo I del Brazo Largo (Caggiano 1979: 115) y Médanos de Escobar (Acosta et al. 2013: 24). Es interesante destacar la similitud de unidades de diseño (áreas punteadas) con La Bellaca 2, ya que este sitio posee un fechado radiocarbónico de $680 \pm 80$ años AP (Rodrigué 2005: 62). Esta edad coincide con la obtenida para TIIBL por lo que, en caso de que se confirme que el evento de inhumación datado esté asociado con el contexto artefactual, los registros cerámicos con las mismas representaciones decorativas tendrían cronologías semejantes.

Una hipótesis esbozada por Rodrigué (2005: 69) y retomada por Acosta et al. (2013: 20) al referirse a la existencia de dos linajes arqueológicos en el área, plantea la existencia de una agrupación de sitios más tardíos ( $\mathrm{La}$ Bellaca 1 y 2 y Guazunambí) con porcentajes mínimos de cerámica incisa. Aunque es posible que haya habido una disminución en la aplicación de técnicas incisas, es necesario considerar otras variables (e.g. patrones diferenciales de descarte en el área excavada) y calcular la proporción de cerámica incisa sobre el NMV, previa realización de remontajes, y no sobre fragmentos (véase discusión en Feely y Ratto 2013). Sobre la base del análisis aquí presentado, se considera que la muestra de TIIBL no está escasamente decorada, aunque es muy posible que presente sesgos. En el NMV pueden estar más representados los bordes incisos (27 de 35) porque es más fácil identificarlos con una vasija particular, mientras que las piezas lisas podrían estar subrepresentadas, ya que es más difícil distinguirlas entre sí (Shapiro 1984) y/o podrían no haber sido recolectadas.

Además de los elementos de diseño recurrentes en los conjuntos cerámicos del Delta Inferior, en el repertorio decorativo de TIIBL se reconocieron representaciones (E24 Figura 6 e) que también aparecen en el Delta Superior del Paraná (Politis et al. 2011: 83). Sin embargo, 
no se hallaron otros modos de representar (apéndices zoomorfos en dos y tres dimensiones) ni formas particulares (campanas, cucharas) que son característicos de la entidad arqueológica Goya-Malabrigo, cuya distribución alcanza el Delta Inferior (Politis y Bonomo 2012). Otras unidades, como las variantes del E3, aparecen representada más al sur, en diversas áreas de la Pampa Húmeda (Rodrigué 2005: 70; véanse ejemplos y citas en Di Prado 2015: 345-359). La recurrencia de ciertos elementos decorativos y variantes del inciso en los repertorios decorativos de la alfarería de una extensa región, es interpretada como el correlato de la circulación de ciertos componentes de los modos de representar en amplias redes de interacción (Di Prado 2015: 345-359). En este sentido, la elevada visibilidad de la decoración en las piezas terminadas favorecería que un amplio rango de personas puedan copiarla o tomarla prestada en diversas situaciones de contacto (Gosselain 2000: 191, 200).

En el conjunto lítico recuperado en TIIBL se destacan los artefactos picados y/o abradidos, los cuales presentan aspectos que fueron observados en distintos conjuntos del Delta Inferior del río Paraná (Bonomo et al. 2009; Matarrese 2015), tales como la baja proporción de artefactos con manufactura, el reciclaje de artefactos fracturados y piezas que estaban agotadas cuando se descartaron. Respecto a la manufactura, si bien el alto grado de fragmentación que presentan algunos de estos artefactos puede haber eliminado rastros de la misma, la escasa formatización puede también ser producto de estrategias de selección de litos con formas apropiadas para su uso. En este sentido, es notable el uso de rodados tanto en artefactos picados/abradidos como en los tallados.

El desarrollo de actividades de molienda en el sitio se evidencia por la presencia de manos de mortero. El hecho de que parte de la formatización de una de las manos se haya orientado a darle mayor confort a la sujeción del artefacto puede asociarse tanto al desarrollo de sesiones prolongadas de molienda como a un aprovechamiento intensivo de las materias primas líticas. No se han hecho aún análisis de fitolitos ni almidones para identificar si existía un complemento hortícola en la subsistencia, como se ha identificado para sitios del Delta Superior del río Paraná asignados a Goya-Malabrigo (Bonomo et al. 2011 b; Colobig y Ottalagano 2013; Cornero y Rangone 2015) y como se registra en las crónicas tempranas (véase síntesis en Bonomo et al. 2011a y b). Por otra parte, el uso de frutos de palmeras está evidenciado por la descripción del diario de campo que menciona "cocos quebrados" (Gaggero 1923:3) y por la presencia de algunos restos carbonizados en la colección, que han sido asignados a pindó (Syagrus romanzoffiana, M.L. Pochettino y P. Arenas com. pers. 2016).

Los yunques con oquedades definidas y superficies redondeadas, alisadas o incluso pulidas (denominados frecuentemente como "rompecocos") pueden haberse utilizado para fracturar frutos de palmeras, donde las morfologías, profundidades y dimensiones de las oquedades permitirían su fijación, prensión manual y fractura (Bonomo et al. 2009). El procesamiento de los frutos de palmera yatay y pindó en el Delta Inferior del río Paraná podría explicar, al menos en parte, el uso de los artefactos de molienda que se encuentran en el área. Los restos de frutos de palmera son relativamente frecuentes en otros sitios del delta tales como el Túmulo 1 del Paraná Guazú y el Túmulo I del Brazo Largo (Caggiano 1977; Loponte 2008; Torres 1911; véase revisión en Bonomo y Capeletti 2014). En algunos casos los hallazgos han sido muy abundantes y estaban asociados a "rompecocos", como registró Torres para el sitio Túmulo I del Paraná Guazú: "El mayor de estos tres ejemplares [trituradores con hoyos] que describo fue retirado del yacimiento de una profundidad de cuarenta centímetros, debajo del cráneo número 7 , donde se encontraba entre un gran amontonamiento de fragmentos de cocos quemados, y aún de cocos enteros de la especie Cocos australis Mart" (=Syagrus romanzoffiana; Torres 1911: 169). La presencia frecuente de frutos de yatay y pindó, en muchos casos quemados, apoya la idea de que efectivamente estos fueron parte de la dieta de las poblaciones del delta y la llanura aluvial del Paraná, por lo menos en la parte final del Holoceno tardío (Acosta 2005; Bonomo et al. 2009; Caggiano 1977; Frenguelli y Aparicio 1923; Torres 1911). Loponte y colaboradores han propuesto que las palmeras eran "manipuladas" por los grupos indígenas del área (Loponte et al. 2012: 230), pero, aunque esta idea es muy atractiva, no han ofrecido ninguna prueba para demostrar tal "manipulación". En otras partes de América se han registrado varias estrategias de manejo de palmeras (tales como la descrita en detalle para los Nukak, véase Politis 2007), que implican una serie de acciones que van más allá del simple consumo inferido a partir de la aparición de endocarpos quemados en los sitios.

La designación de TIIBL, por parte de Gaggero y Fernández, como un "montículo", sugiriendo que se trata de una estructura de origen cultural, parece ser probable. Si bien se desconoce si su formación se debió al aporte ad hoc de sedimentos o solo al crecimiento por acreción, la descripción del sitio, su lejanía del albardón natural, su forma circular y las fotos que acompañan el informe apoyan este origen. El otro punto es que es una estructura circular y relativamente pequeña (como el Túmulo ॥ de Paraná Guazú -22 m de diámetro- y el Túmulo I del Brazo Largo), distinta a las estructuras de filiación GoyaMalabrigo, que son en general elípticas (a excepción de Puesto Acosta) y más grandes (eje menor $=69,7$ a 22,5 m; eje mayor $=80,4$ a 35,4 m) (Bonomo et al. 2011b; Castiñeira et al. 2013).

Es difícil asociar el contexto de TIIBL a alguno de los dos linajes arqueológicos propuestos por Loponte y colaboradores (Acosta et al. 2013; Loponte et al. 2012) 
ya que estos autores definen "linajes arqueológicos" sobre la base de "paquetes de rasgos" que tienen en cuenta la incidencia de los peces en la dieta, el grado de fragmentación de las carcasas, la forma de los tembetás o de los botones labiales, el empleo de materia prima lítica y la proporción de cerámica incisa. Respecto a los dos primeros puntos, en el caso del TIIBL, como se dijo previamente, los sesgos derivados de las técnicas de excavación probablemente implicaron la pérdida de los especímenes óseos pequeños (como restos ictiológicos y lascas óseas). Por lo tanto, al igual que sucede con otras colecciones del área, es difícil evaluar la importancia de los peces dentro del conjunto arqueofaunístico, así como la intensidad de la fragmentación de las carcasas. Por otro lado, los tembetás o botones labiales son excepcionales en el registro y como lo reconocen los autores (Loponte et al. 2012: 225) su recuperación en los sitios está fuertemente influida por el tamaño del muestreo. Además, la información disponible es aún insuficiente para distinguir si estas diferencias representan "linajes arqueológicos" distintos o si por el contrario están vinculadas a las variaciones estacionales en la explotación del ambiente, a las funcionalidades de los sitios, a su distancia a las materias primas o a las áreas de actividad intrasitio que fueron muestreadas con las excavaciones.

Las características resumidas para TIIBL son semejantes a las de otros sitios cercanos de las islas del Delta Inferior, como Túmulo I del Brazo Largo, Brazo Largo, Túmulo I y II del Paraná Guazú, Paraná Ibicuy 1 y 5 y Túmulo I del Brazo Gutiérrez (Caggiano 1984; Torres 1911) (Figura 1). A su vez, este conjunto de sitios muestra algunas diferencias con los contextos asociados a Goya-Malabrigo, lo cual expresa la variabilidad del registro arqueológico del Delta del Paraná durante el Holoceno tardío (véase Bonomo et al. 2011a). Esta variabilidad ya fue notada tempranamente por otros autores (e.g. Aparicio 1948; Torres 1911) y luego se propusieron entidades arqueológicas diferentes para dar cuenta de algunas propiedades particulares del registro en el Delta Inferior: Fase Ibicuy de la Cultura Entrerriana según Serrano (1972: 22-27), complejo Ibicueño, según Rodríguez (2001) y Facie Ibicueña de la Cultura Entrerriana (Caggiano 1984: 42-43). Estos contextos del Delta Inferior representarían un modo de vida -hidrocentralidad- similar al inferido para Goya-Malabrigo (véase Politis y Bonomo 2012). Sin embargo, se reconocieron algunas diferencias en la alfarería (ciertas formas y elementos decorativos) que aún deben ser exploradas. Todavía no ha sido posible discutir en estos contextos la presencia de una horticultura a pequeña escala, como en el caso de Goya-Malabrigo, porque no se han hecho los estudios correspondientes. Sin embargo, la explotación de frutos de palmeras parece ser mayor que la registrada en el Delta Superior.

Estos sitios tardíos del Delta Inferior representan trayectorias históricas específicas y podrían ser la expresión arqueológica de la diversidad étnica que registraron los cronistas europeos cuando llegaron a la región, en el siglo XVI. Entendiendo que las etnias son alteridades socioculturales colectivas (Bechis 2010) creadas, mantenidas, modificadas y, eventualmente, disueltas por procesos históricos e identitarios, es probable que dentro de lo que se denominó complejo chaná-timbú (véase Serrano 1955; Politis y Bonomo 2012) existieran similitudes en el modo de vida y algunas diferencias dialectales y otras vinculadas con procesos de identificación y diferenciación social que se objetivaron en la cultura material. A partir del análisis de estos procesos, se podría explorar si estas características diferentes, que permiten distinguir los sitios mencionados de la entidad Goya-Malabrigo, se vinculan con algunas de las etnias (por ejemplo los mbegúa o chaná-mbeguá) que se reconocieron en el Delta del Paraná en el siglo XVI.

La Plata, 29 de septiembre de 2016

\section{Agradecimientos}

Este estudio fue realizado dentro del proyecto "Arqueología de ambientes acuáticos del centro-este argentino" FCNyM, UNLP (11/N770) y del INCUAPACONICET, Facultad de Ciencias Sociales, UNICEN. Se recibió además un subsidio de National Geographic Society's Committee for Research and Exploration para el proyecto "Farming, Mound Building, and Social Complexity in the Upper Delta of the Paraná River". Los autores agradecen a las Dras.María L. Pochettino y Patricia Arenas por la identificación de los restos vegetales, al Lic. Diego Gobbo, personal técnico de la División Arqueología del MLP, por la asistencia con las figuras y a la encargada del Depósito 25 de la División Arqueología de la misma institución, Dra. Ana Igareta.

\section{Bibliografía}

Acosta, A. 2005. "Zooarqueología de cazadores-recolectores del extremo nororiental de la provincia de Buenos Aires (humedal del río Paraná inferior, Región Pampeana, Argentina)". Facultad de Ciencias Naturales y Museo, Universidad Nacional de La Plata, La Plata, Argentina, 332 p. Tesis Doctoral. FCNyM, UNLP.

Acosta, A., N. Buc, M. Ramírez, F. Prevosti y D. Loponte. 2015. Producción y uso de objetos ornamentales elaborados sobre dientes de carnívoros en contextos arqueológicos del Humedal del Paraná Inferior. Revista del Museo de Antropología, 8 (2): 33-46.

Acosta, A., D. Loponte y C. García Esponda. 2011. Primer registro de perro doméstico prehispánico (Canis familiaris) entre los grupos cazadores recolectores del humedal de Paraná inferior (Argentina). Antípoda. Revista de Antropología y Arqueología, 13: $175-199$.

Acosta, A., D. Loponte y P. Tchilinguirian. 2013. Nuevos aportes para la arqueología del Humedal del Paraná Inferior: el sitio Médanos de Escobar. Relaciones de la Sociedad Argentina de Antropología, XXXVIII (1): 19-35.

Adams, J. L. 2002. Ground Stone Analysis. A technological 
approach. The University of Utah Press, Salt Lake City.

Andrews, P. 1990. Ow/s, Caves and Fossils. University of Chicago Press, Chicago.

Aparicio, F. 1948. The coastal and Amazonian Tupi. The Archaeology of the Paraná River. Handbook of South American Indians, 3: 56-67.

Averbouh, A. 2000. “Technologie de la matière osseuse travaillée et implications peleothnologiques. L'exemple des chaînes d'exploitation du bois de cervidé chez les Magdaléniens des Pyrénées». Universidad de París, París, Francia, 500 p. Tesis doctoral. Universidad de París.

Balfet, H., M-F. Fauvet-Berthelot y S. Monzón. 1992.Normas para la descripción de vasijas cerámicas. Centro de Estudios Mexicanos y Centroamericanos, México D.F.

Behrensmeyer, A. 1978. Taphonomic and ecologic information from bone weathering. Paleobiology, 4: 150-162.

Bechis, M. 2010. Piezas de Etnohistoria y de Antropología Histórica. Sociedad Argentina de Antropología, Buenos Aires.

Babot, M. P. 2004. "Tecnología y utilización de artefactos de molienda en el Noroeste prehispánico". Facultad de Ciencias Naturales e I.M.L., Universidad Nacional de Tucumán, San Miguel de Tucumán, Argentina, 442 p. Tesis Doctoral. F.C.N. e I.M.L, UNT.

Binford, L. R. 1981. Bones, Ancient Men and Modern Myths. Studies in Archaeology. Academic Press, London.

Bonomo, M. 2006. Un acercamiento a la dimensión simbólica de la cultura material en la región pampeana. Relaciones de la Sociedad Argentina de Antropología, XXXI: 89-115.

Bonomo, M. 2013. Reanálisis de la colección de Samuel Lothrop procedente del Delta del Paraná. Relaciones de la Sociedad Argentina de Antropología, 38 (1): 169-198.

Bonomo, M., F. J. Aceituno, G. Politis y M. L. Pochettino. 2011b. Pre-Hispanic horticulture in the Paraná Delta (Argentina): archaeological and historical evidence. World Archaeology, 43 (4): 554-575.

Bonomo, M., I. Capdepont y A. Matarrese. 2009. Alcances y limitaciones en el estudio de colecciones. Los materiales arqueológicos del Delta del río Paraná depositados en el Museo de La Plata. Revista de Arqueología Sudamericana, 5 (1): 68-101.

Bonomo, M. y L. Capeletti. 2014. Uso prehispánico de las palmeras Syagrus romanzoffiana y Butia yatay en el Nordeste argentino: aportes desde la etnografía y la biometría. Revista del Museo de Antropología, 7 (2): 227-234.

Bonomo, M., G. Politis y C. Gianotti. 2011a. Montículos, jerarquía social y horticultura en las sociedades indígenas del delta del río Paraná (Argentina). Latin American Antiquity, 22 (3): 397-333.

Bugliani, M. F. 2008. Consumo y representación en el sur de los valles calchaquíes (Noroeste argentino): los conjuntos cerámicos de las aldeas del primer milenio A.D. BAR International Series S1774, Archaeopress, Oxford.

Caggiano, M. A. 1977. Contribución a la arqueología del Delta del Paraná. Obra del centenario del Museo de La Plata. Antropología, II: 301-324.

Caggiano, M. A. 1979. “Análisis y desarrollo cultural prehispánico en la cuenca inferior del Plata". Facultad de Ciencias Naturales y Museo, Universidad Nacional de La Plata, La Plata, Argentina, 318 p. Tesis Doctoral. FCNyM, UNLP.

Caggiano, M. A. 1984. Prehistoria del noreste argentino, sus vinculaciones con la República Oriental del Uruguay y sur de Brasil. Pesquisas, Antropología, 38: 5-109.

Caggiano, M. A., E. Goñi y M. I. Barrientos. 2003. Registro arqueológico en el Delta del Paraná. Hacia una aproximación de las manifestaciones culturales autóctonas. Actas del $8^{\circ}$ Encuentro de Historia Regional del Norte Bonaerense y Sur Santafesino, San Pedro.

Castiñeira, C., A. Blasi, G. Politis, M. Bonomo, L. del Puerto, R. Huarte, J. Carbonari, F. Mari y F. García-Rodríguez. 2013. The Origin and Construction of Pre-Hispanic Mounds in the Upper Delta of the Paraná River (Argentina). Archaeological and Anthropological Sciences, 5: 37-57.

Colobig, M. M. y F. Ottalagano. 2013. Contextos de uso y consumo de vegetales por grupos cazadores-recolectores sudamericanos del Holoceno tardío: primeros estudios paleoetnobotánicos en la cuenca del Paraná medio. Actas del XVIII Congreso Nacional de Arqueología Argentina: 71, La Rioja.

Convención Nacional de Antropología. 1966. Facultad de Filosofía y Humanidades, Córdoba.

Cornero, S. y L. Rangone. 2015. Análisis arqueobotánicos en sitios de la entidad arqueológica Goya-Malabrigo ubicados en el centro-norte de Santa Fe. Anuario de Arqueología, 7: 85-94.

Di Prado, V. 2015. "Estudio comparativo de las prácticas de elaboración y uso de la alfarería prehispánica del centro-este de Argentina desde una perspectiva macrorregional". Facultad de Ciencias Naturales y Museo, Universidad Nacional de La Plata, Argentina, 447 p. Tesis Doctoral. FCNyM, UNLP.

Escosteguy, P. y M. Vigna. 2010. Experimentación en el procesamiento de Myocastor coypus. M. Berón, L. Luna, M. Bonomo, C. Montalvo, C. Aranda y M. Carrera Aizpitarte editores, Mamül Mapu: pasado y presente desde la arqueología pampeana, Tomo I, pp. 293-307, Editorial Libros del Espinillo, Ayacucho.

Feely, A. y N. Ratto. 2013. Cálculo del número mínimo de vasijas y recolección superficial: criterios metodológicos y análisis de casos del oeste tinogasteño (Catamarca). Andes, 24: 425-445.

Fisher, J. 1995. Bone surface modifications in zooarchaeology. Journal of Archaeological Method and Theory, 2 (1): 7-68.

Frenguelli, J. y F. de Aparicio. 1923. Los paraderos de la margen derecha del río Malabrigo (Departamento de Reconquista, Prov. de Santa Fe). Anales de la Facultad de Ciencias de la Educación, I: 7-112. 
Gaggero, P. 1923. El túmulo indígena II del Brazo Largo (Delta del Paraná - Provincia de Entre Ríos) explotado en el mes de Mayo de 1923. (Preliminar). Universidad Nacional de La Plata, Instituto del Museo. 1924. Nros 6065-78. 7pp. Ms.

Gatto, S. 1939. El paradero-cementerio de Brazo Largo (Delta del Paraná). Physis, 16: 365-376.

Gosselain, O. P. 2000. Materializing Identities: An African Perspective. Journal of Archaeological Method and Theory, 7 (3): $187-217$.

Gutiérrez, M. 2004. “Análisis Tafonómicos en el área Interserrana (Provincia de Buenos Aires)". Facultad de Ciencias Naturales y Museo, Universidad Nacional de La Plata, Argentina, 533 p. Tesis Doctoral. FCNyM, UNLP.

Gutiérrez, M. y C. Kaufmann. 2007. Criteria for the Identification of Formation Processes in Guanaco (Lama guanicoe) Bone Assemblages in Fluvial-Lacustrine Environnments. Journal of Taphonomy, 5 (4): 151-176.

Kozák, V., D. Baxter, L. Williamson y R. L. Carneiro. 1979. The Héta Indians: fish in a dry pond. Anthropological Papers of the American Museum of Natural History, vol. 55 (6). American Museum of Natural History, New York.

Kröhling, D. M. 2009. La Formación El Palmar, una unidad fluvial asignable al subestadio cálido EIO5a (Pleistoceno Tardío) de la cuenca del río Uruguay. Natura Neotropicalis, 40 (1): 61-86.

Kusch, M. F. y D. C. Conlazo. 1984. Yacimiento Ezeiza: análisis del tipo de ornamentación que caracteriza a la muestra de fragmentos decorados obtenidos en el mismo. ADHEA, V: 6-16.

Lloveras, L., M. Moreno-García y J. Nadal. 2009. Butchery, Cooking and Human Consumption Marks on Rabbit (Oryctolagus cuniculus) Bones: An Experimental Study.Journal of Taphonomy, 7 (2-3): 179-201.

Lopes de Sousa, P. [1530-1532] 1839. Diario da Navegaçao de Pero Lopes de Sousa. Typographia da Sociedade Propagadora dos Conhecimientos Uteís, Lisboa.

López, M. A. 2000-2002. Técnicas de acabado de superficie de la cerámica arqueológica: indicadores macro y microscópicos. Una revisión sobre las técnicas de estudio más habituales. Cuadernos del Instituto Nacional de Antropología y Pensamiento Latinoamericano, 19: 347-364.

Loponte, D. 2008. Arqueología del Humedal del Paraná Inferior: Bajíos Ribereños Meridionales. Instituto Nacional de Antropología y Pensamiento Latinoamericano, Buenos Aires.

Loponte, D., A. Acosta y L. Mucciolo. 2012. Contribución a la arqueología del Delta del Paraná: el nivel acerámico del sitio Isla Lechiguanas 1. Comechingonia, 16 (1): 207-246.

Loponte, D. y M. Pérez (compiladores). 2013. Cerámica Prehispánica de Tierras Bajas de Argentina, Vol. I. Instituto Nacional de Antropología y Pensamiento Latinoamericano, Buenos Aires.

Lothrop, S. 1932. Los indios del Delta del Paraná. Annals of the New York Academy of the Sciences, 33: 77-232.
Lyman, R. 1994. Vertebrate Taphonomy. Cambridge Manuals in Archaeology, Cambridge University Press, Cambridge.

Lyman, R. 2008. Quantitative Paleozoology. Cambridge University Press, Cambridge.

Mallye, J.-B. 2011. Réflexion sur le dépouillement des petits carnivores en contexte archéologique: apport de I'expérimentation. Archaeofauna, 20: 7-25.

Matarrese, A. 2015. Tecnología lítica prehispánica del Delta del Paraná: los artefactos picados y/o abradidos. Libro de Resúmenes del VI Encuentro de Discusión Arqueológica del Nordeste Argentino: 68. Gualeguaychú.

Mazza, B. 2015. Colecciones antiguas, datos nuevos: Primeros resultados del análisis de las colecciones bioarqueológicas del Humedal del Paraná Inferior. Revista del Museo de Antropología, 8 (1): 133-146.

Mengoni Goñalons, G. L. 2010. Zooarqueología en la práctica. Algunos temas metodológicos. Xama, 19: 83-113.

Outram, A. K. 2001. A new approach to identifying bone marrow and grease exploitation: why the "Indeterminate" fragments should not be ignored. Journal of Archaeological Science, 28: 401- 410.

Pérez Jimeno, L. y N. Buc. 2010. Tecnología ósea en la cuenca del Paraná. Integrando los conjuntos arqueológicos del tramo medio e inferior. M. Berón, L. Luna, M. Bonomo, C. Montalvo, C. Aranda y M. Carrera Aizpitarte editores, Mamül Mapu: pasado y presente desde la arqueología pampeana, Tomo I, pp. 115127, Libros del Espinillo, Ayacucho.

Petrocelli, J. 1975. Nota preliminar sobre hallazgos arqueológicos en el Valle del Río Luján (Población Río Luján, Campana, Provincia de Buenos Aires). Actas I Congreso Arqueología Argentina, pp. 251-270. Rosario.

Politis, G. 2007. Nukak.Ethnoarchaeology of an Amazonian People. University College London Institute of Archaeology Publications, Left Coast Press, Walnut Creek.

Politis, G. y M. Bonomo. 2012. La entidad arqueológica GoyaMalabrigo (ríos Paraná y Uruguay) y su filiación arawak. Revista de Arqueología, 25 (1): 10-46.

Politis, G. G., M. Bonomo, C. Castiñeira y A. Blasi. 2011. Archaeology of the Upper Delta of the Paraná River (Argentina): Mound Construction and Anthropic Landscapes in the Los Tres Cerros locality. Quaternary International, 245: 74-88.

Prates, L. 2014. Crossing the boundary between humans and animals: the extinct fox Dusicyon avus from a hunter-gatherer mortuary context in Patagonia (Argentina).Antiquity, 88: 12011212.

Prevosti, F., M. Bonomo y E. Tonni. 2004. La distribución de Chrysocyon brachyurus (Illiger, 1811) (Mammalia: Carnivora: Canidae) durante el Holoceno en la Argentina: implicancias paleoambientales. Mastozoología Neotropical,11 (1): 27-43.

Prous, A. y M. Alonso. 2010. As indústrias líticas dos ceramistas tupiguarani. A. Prous y T. Andrade Lima editores, Os ceramistas 
Tupiguarani. Tomo III, pp. 27-76, IPHAN, Belo Horizonte.

Relaño, F. 2005. Le plan secret de Magellan. C. de CastelnauL'Estoile y F. Regourd editores, Connaissances et Pouvoirs. Les espaces impériaux (XVIe-XVIIle siècles) France, Espagne, Portugal, pp. 25-38, Presses Universitaires de Bordeaux.

Rodríguez, J. A. 2001. Poblamiento prehistórico de la Mesopotamia Argentina. Folia Histórica del Nordeste, 15: 129-146.

Rodrigué, D. 2005. El estilo en la cerámica del Humedal del Paraná. La Zaranda de Ideas, 1 (1): 59-75.

Rye, O. S. 1981. Pottery Technology. Principles and Reconstruction. Taraxacum, Washington.

Salemme, M. y E. P. Tonni. 1983. Paleoetnozoología de un sitio arqueológico en la Pampa Ondulada: sitio Río Luján (partido de Campana, provincia de Buenos Aires). Relaciones de la Sociedad Argentina de Antropología, 15: 77-90.

Schuller, R. 1915. A nova Gazeta da Terra do Brasil (Newen Zeytungauss Presillg Landt) e sua origen mais provavel. Annaes da Bibliotheca Nacional do Rio de Janeiro, XXXIII: 115-143.

Segura, V., F. Prevosti y G. Cassini. 2013. Cranial ontogeny in the Puma lineage, Puma concolor, Herpailurus yagouaroundi, and Acinonyx jubatus (Carnivora: Felidae): a three-dimensional geometric morphometric approach. Zoological Journal of the Linnean Society, 169 (1): 235-250.

Serrano, A. 1955. Los pueblos y culturas indígenas del Litoral. El Litoral, Santa Fe.
Serrano, A. 1972. Líneas fundamentales de la arqueología del litoral (una tentativa de periodización). Instituto de Antropología, Córdoba.

Shapiro, G. 1984. Ceramic vessels, site permanence, and group size: a Mississippian example. American Antiquity, 49 (4): 696-712.

Silvestre, R. y N. Buc. 2015. Experimentação e Traceologia: explorando a funcionalidade dos "calibradores" dos sítios arqueológicos de tradição Tupiguarani, Argentina. Teoria \& Sociedade, 23: 125-151.

Skibo, J. M. 1992. Pottery function. A use alteration perspective. Plenum Press, Nueva York y Londres.

Tedford, R. H., B. E. Taylor y X. Wang. 1995. Phylogeny of the Caninae (Carnivora: Canidae): the living taxa. American Museum Novitates, 3146: 1-37.

Torres, L. M. 1911. Los primitivos habitantes del Delta del Paraná. Universidad Nacional de La Plata, Biblioteca Centenaria 4, Buenos Aires.

Veroslavsky, G. y M. Ubilla. 2007. A 'snapshot' of the evolution of the Uruguay River (Del Plata Basin): the Salto depositional sequence (Pleistocene, Uruguay, South America). Quaternary Science Reviews, 26 (22): 2913-2923.

Vieugué, J. 2014. Use-wear analysis of prehistoric pottery: methodological contributions from the study of the earliest ceramic vessels in Bulgaria (6100-5500 BC). Journal of Archaeological Science, 41: 622-630. 